\title{
Analysis of classical and first-order shear deformable cracked orthotropic plates
}

\section{András Szekrényes}

\begin{abstract}
The Kirchhoff and Mindlin plate theories are applied in this study to calculate the stresses and the energy release rates in delaminated orthotropic composite plates. A novel double-plate system is developed with the imposition of the kinematic continuity constraints in the interface plane. The governing equations of the system were derived in both cases. As a demonstrative example a simply-supported plate subjected to a point force was analyzed using Lévy plate formulation and the problem was solved by a state-space model. The distribution of the stress resultants and the interlaminar stresses in the uncracked part were also determined. Moreover, the distributions of the mode-II and mode-III energy release rates along the crack front were calculated by the J-integral. The 3D finite element model of the plate was created providing reference data for the analytical model. The results show that the displacement and stress fields obtained from the Kirchhoff and Mindlin theories are quite similar, but in the case of the energy release rates, transverse shear effect is necessary to consider to obtain reasonably good agreement between the analytical and numerical results.
\end{abstract}

\section{Keywords}

Laminated plate, delamination, J-integral, Mixed-mode II/III fracture, Classical laminated plate theory, first-order plate theory

\section{Introduction}

Linear plate theories play important role in the design of composite, ${ }^{1,2}$ steel $^{3}$ and sandwich structures ${ }^{4}$ in the engineering life. The interlaminar fracture is one of the primary failure modes in composite and sandwich structures during transverse and sudden impact loading, as well. The fracture behavior of laminated materials is characterized by the energy release rate (ERR). ${ }^{5}$ The critical value of this global parameter (critical energy release rate - CERR) is the limit value to proportionate the structures against delamination failure. Within the scope of linear elastic fracture mechanics, ${ }^{5}$ the basic failure modes include mode-I (opening mode), mode-II (in-plane shear) and mode-III (anti-plane shear), respectively. The fracture resistance under these modes is determined through standard or nonstandard tests. The significant part of the literature deals with mode-I, ${ }^{6,7}$ mode-II ${ }^{8-10}$ and mixed-mode $\mathrm{I} / \mathrm{II}^{10-12}$ cases. However, in the last decades, more and more emphasis was put on the investigation of modeIII. $^{13-20}$ fracture, later even the combined mode II/III, ${ }^{21-29} \mathrm{I} / \mathrm{III}^{30,31}$ and I/II/III ${ }^{32-34}$ conditions were taken into account. The latest developments for possible acceptable tests under mode-III, ${ }^{16-18}$ mixedmode II/III ${ }^{22}$ and mixed-mode $\mathrm{I} / \mathrm{III}^{30}$ equally involve plate-type specimens with rectangular delamination surface.

In general, an analytical solution can be easily developed for beam-type specimens; in contrast, for platetype samples the analytical solutions - mainly because of the complex boundary conditions - are not available. Therefore, without any exception, the data reduction is always made by the finite element method (FEM) incorporating the virtual-crack closure technique $(\mathrm{VCCT})^{19}$ and cohesive zone model $(\mathrm{CZM})^{30}$ applications. For delaminated plates, Davidson et al. ${ }^{35}$ applied shell elements with interface constraints to calculate the ERRs, Sankar and Sonik ${ }^{36}$ performed similar

Department of Applied Mechanics, Budapest University of Technology and Economics, Hungary

\section{Corresponding author:}

András Szekrényes, Department of Applied Mechanics, Budapest University of Technology and Economics, Budapest, Múegyetem rkp 5 , Building MM, H-I III, Hungary.

Email: szeki@mm.bme.hu 
computations. The crack tip force method (CTFM $)^{37}$ is a similar solution to the VCCT, utilizing the crack tip forces to calculate and separate the ERRs. However, its result does not differ from that of a VCCT analysis. The main problem of the FE models is that a $3 \mathrm{D}$ model is necessary to construct and the VCCT is available only in few FE packages (e.g. in ABAQUS and NASTRAN, but not available in ANSYS and COSMOS/M) as a built-in command. In accordance with this overview, we can also conclude that there are no analytical solutions available for delaminated composite plate specimens as possible data reduction schemes.

The aim of this paper is to present the application of classical laminated plate theory (Kirchhoff plate theory or CLPT) ${ }^{2,38-40}$ and first-order shear deformable plate theory (Mindlin plate theory or FSDT) ${ }^{2-4}$ to calculate the stresses and ERRs in delaminated plates with symmetrical lay-up and straight delamination front under mixed-mode II/III condition. First, the displacement field is formulated by imposing the interface constraints. Second, the basic equations of linear elasticity are applied to derive the strain and stress fields in elastic orthotropic composite plates. The present formulation does not incorporate arbitrarily defined parameters (e.g. shear compliances, ${ }^{41-46}$ ) and it is shown that the developed model is physically consistent with the equations of linear elasticity. As an example, a simply-supported plate subjected to a point force is analyzed applying the state-space model. ${ }^{2}$ The distribution of the interlaminar stresses is calculated, moreover, the $J$-integral ${ }^{47,48}$ is utilized to determine the distribution of the mode-II and mode-III ERRs along the crack front. An FE model is also created and the numerical results are compared to those obtained by analysis. The relatively good agreement obtained shows the usefulness of plate theories in delamination analysis.

\section{FSDT- Mindlin plate theory, general formulation}

We assume that a delaminated plate with straight crack front lies in the $x-y$ plane and the crack front is parallel to the $y$ axis. The plate theory presented in this section is utilized to capture the displacement and stress fields in the delaminated portion of an elastic laminated orthotropic plate with symmetric lay-up presented in Figure 1. The thickness of the top and bottom plates is $t$. The assumed displacement field based on FSDT for elastic plates can be written as: ${ }^{2}$

$$
\begin{aligned}
& u_{\alpha}(x, y, z)= \pm u_{0}(x, y)+\theta_{\mathrm{x}}(x, y) \cdot z, \\
& v_{\alpha}(x, y, z)= \pm v_{0}(x, y)+\theta_{\mathrm{y}}(x, y) \cdot z,
\end{aligned}
$$

where $\alpha$ takes "top" and the upper sign for the top plate element in Figure 1(a) and $\alpha$ takes "bot" and the lower sign for the bottom plate element of the delaminated portion in Figure 1(b). Moreover, $u_{0}$ and $v_{0}$ are the constant parts of the displacements, $\theta_{\mathrm{x}}$ and $\theta_{\mathrm{y}}$ are the rotations of the cross section about the $y$ and $x$ axes, respectively. In this paper, only mixed-mode II/III problems are considered, i.e. the crack opening is zero.

Therefore, the transverse deflection, $w=w(x, y)$ is the same for both the top and bottom plates. Applying the basic equations of linear elasticity ${ }^{49}$ for an orthotropic plate we obtain the strain and stress fields, then by integrating the stresses over the thickness, the stress resultants in terms of strains and shear strains become: ${ }^{2}$

$$
\begin{gathered}
\left\{\begin{array}{c}
\{N\} \\
\{M\}
\end{array}\right\}=\left[\begin{array}{cc}
{[A]} & {[0]} \\
{[0]} & {[D]}
\end{array}\right]\left\{\begin{array}{l}
\left\{\varepsilon^{(0)}\right\} \\
\left\{\varepsilon^{(1)}\right\}
\end{array}\right\}, \\
Q_{\mathrm{x}}=k A_{55} \gamma_{\mathrm{xz}}, \quad Q_{\mathrm{y}}=k A_{44} \gamma_{\mathrm{yz}},
\end{gathered}
$$

where $\{N\}^{\mathrm{T}}=\left\{N_{\mathrm{x}}, N_{\mathrm{y}}, N_{\mathrm{xy}}\right\}$ is the vector of in-plane normal and shear forces, $\{M\}^{\mathrm{T}}=\left\{M_{\mathrm{x}}, M_{\mathrm{y}}, M_{\mathrm{xy}}\right\}$ is the vector of bending and twisting moments, $Q_{\mathrm{x}}, Q_{\mathrm{y}}$ are the shear forces and $k=5 / 6$ is the shear correction factor. ${ }^{2,3}$ Moreover, $\left\{\varepsilon^{(0)}\right\}$ and $\left\{\varepsilon^{(1)}\right\}$ are the vectors of constant and linear strains, finally $\gamma_{\mathrm{xz}}$ and $\gamma_{\mathrm{yz}}$ are the shear strains. The stress resultants can be calculated from the integration of the stresses in the throughthickness direction: ${ }^{2}$

$$
\left\{\begin{array}{c}
N_{\alpha \beta} \\
M_{\alpha \beta}
\end{array}\right\}=\int_{-t / 2}^{t / 2} \sigma_{\alpha \beta}\left\{\begin{array}{l}
1 \\
z
\end{array}\right\} d z, Q_{\alpha}=\int_{-t / 2}^{t / 2} \tau_{\alpha z} d z,
$$

where $\alpha$ and $\beta$ take the symbols $x$ and $y$. The stiffness parameters are defined as: ${ }^{1,2}$

$$
A_{\mathrm{ij}}, D_{\mathrm{ij}}=\sum_{k=1}^{N_{l}} \int_{z_{\mathrm{k}}}^{z_{k+1}} \bar{C}_{\mathrm{ij}}^{(k)}\left(1, z^{2}\right) d z
$$

where the reference plane is the local midplane of the top and bottom plates, respectively (refer to Figure 1). The vectors of strains are written as:

$$
\left\{\begin{array}{c}
\varepsilon_{\mathrm{x}} \\
\varepsilon_{\mathrm{y}} \\
\gamma_{\mathrm{xy}}
\end{array}\right\}=\left\{\begin{array}{c}
\varepsilon_{\mathrm{x}}^{(0)} \\
\varepsilon_{\mathrm{y}}^{(0)} \\
\gamma_{\mathrm{xy}}^{(0)}
\end{array}\right\}+z\left\{\begin{array}{c}
\varepsilon_{\mathrm{x}}^{(1)} \\
\varepsilon_{\mathrm{y}}^{(1)} \\
\gamma_{\mathrm{xy}}^{(1)}
\end{array}\right\},\left\{\begin{array}{l}
\gamma_{\mathrm{xz}} \\
\gamma_{\mathrm{yz}}
\end{array}\right\}=\left\{\begin{array}{l}
\gamma_{\mathrm{xz}}^{(0)} \\
\gamma_{\mathrm{yz}}^{(0)}
\end{array}\right\},
$$


where

$$
\left\{\begin{array}{c}
\varepsilon_{\mathrm{x}}^{(0)} \\
\varepsilon_{\mathrm{y}}^{(0)} \\
\gamma_{\mathrm{xy}}^{(0)}
\end{array}\right\}=\left\{\begin{array}{c}
\frac{\partial u_{0}}{\partial x} \\
\frac{\partial v_{0}}{\partial x} \\
\frac{\partial u_{0}}{\partial y}+\frac{\partial v_{0}}{\partial x}
\end{array}\right\},\left\{\begin{array}{c}
\varepsilon_{\mathrm{x}}^{(1)} \\
\varepsilon_{\mathrm{y}}^{(1)} \\
\gamma_{\mathrm{xy}}^{(1)}
\end{array}\right\}=\left\{\begin{array}{c}
\frac{\partial \theta_{\mathrm{x}}}{\partial x} \\
\frac{\partial \theta_{\mathrm{y}}}{\partial x} \\
\frac{\partial \theta_{\mathrm{x}}}{\partial y}+\frac{\partial \theta_{\mathrm{y}}}{\partial x}
\end{array}\right\},\left\{\begin{array}{l}
\gamma_{\mathrm{xz}}^{(0)} \\
\gamma_{\mathrm{yz}}^{(0)}
\end{array}\right\}=\left\{\begin{array}{c}
\theta_{\mathrm{x}}+\frac{\partial w}{\partial x} \\
\theta_{\mathrm{y}}+\frac{\partial w}{\partial y}
\end{array}\right\}
$$

Formulating the total potential energy for the elastic plate subjected to transverse load and deriving the Euler-Lagrange equations, we obtain the equilibrium equations in the following forms: ${ }^{2,3}$

$$
\begin{gathered}
\frac{\partial N_{\mathrm{x}}}{\partial x}+\frac{\partial N_{\mathrm{xy}}}{\partial y}=0, \frac{\partial N_{\mathrm{xy}}}{\partial x}+\frac{\partial N_{\mathrm{y}}}{\partial y}=0, \\
\frac{\partial M_{\mathrm{x}}}{\partial x}+\frac{\partial M_{\mathrm{xy}}}{\partial y}-Q_{\mathrm{x}}=0, \frac{\partial M_{\mathrm{xy}}}{\partial x}+\frac{\partial M_{\mathrm{y}}}{\partial y}-Q_{\mathrm{y}}=0, \\
\frac{\partial Q_{\mathrm{x}}}{\partial x}+\frac{\partial Q_{\mathrm{y}}}{\partial y}+q=0
\end{gathered}
$$

Taking the stress resultants back into equation (7) and (8), we obtain:

$$
\begin{gathered}
A_{11} \frac{\partial^{2} u_{0}}{\partial x^{2}}+A_{66} \frac{\partial^{2} u_{0}}{\partial y^{2}}+\left(A_{12}+A_{66}\right) \frac{\partial^{2} v_{0}}{\partial x \partial y}=0, \\
A_{22} \frac{\partial^{2} v_{0}}{\partial y^{2}}+A_{66} \frac{\partial^{2} v_{0}}{\partial x^{2}}+\left(A_{12}+A_{66}\right) \frac{\partial^{2} u_{0}}{\partial x \partial y}=0, \\
D_{11} \frac{\partial^{2} \theta_{x}}{\partial x^{2}}+D_{66} \frac{\partial^{2} \theta_{x}}{\partial y^{2}}+\left(D_{12}+D_{66}\right) \frac{\partial^{2} \theta_{y}}{\partial x \partial y} \\
-k A_{55}\left(\theta_{x}+\frac{\partial w}{\partial x}\right)=0,
\end{gathered}
$$

$$
\begin{gathered}
D_{22} \frac{\partial^{2} \theta_{y}}{\partial y^{2}}+D_{66} \frac{\partial^{2} \theta_{y}}{\partial x^{2}}+\left(D_{12}+D_{66}\right) \frac{\partial^{2} \theta_{x}}{\partial x \partial y} \\
-k A_{44}\left(\theta_{y}+\frac{\partial w}{\partial y}\right)=0, \\
k A_{55}\left(\frac{\partial \theta_{x}}{\partial x}+\frac{\partial^{2} w}{\partial x^{2}}\right)+k A_{44}\left(\frac{\partial \theta_{y}}{\partial y}+\frac{\partial^{2} w}{\partial y^{2}}\right)=-q
\end{gathered}
$$

where $A_{\mathrm{ij}}$ and $D_{\mathrm{ij}}$ are stiffness parameters and $q=q(x, y)$ is the external load of the plate.

\section{FSDT with interface constraint}

The FSDT utilized in this section is based on an assumed displacement field including interface constraints to formulate the model of the uncracked region of a delaminated orthotropic composite plate. The mathematical form of in-plane displacement components are the same as those given by equations (1); however, we have to ensure the displacement continuity between the top and bottom plate elements shown by Figure 1. The interface constraint equations of the uncracked portion are

$$
\left.u_{\text {top }}\right|_{z=-\frac{t}{2}}=\left.u_{\text {bot }}\right|_{z=\frac{t}{2}},\left.\quad v_{\text {top }}\right|_{z=-\frac{t}{2}}=\left.v_{\text {bot }}\right|_{z=\frac{t}{2}}
$$

(a)

(b)

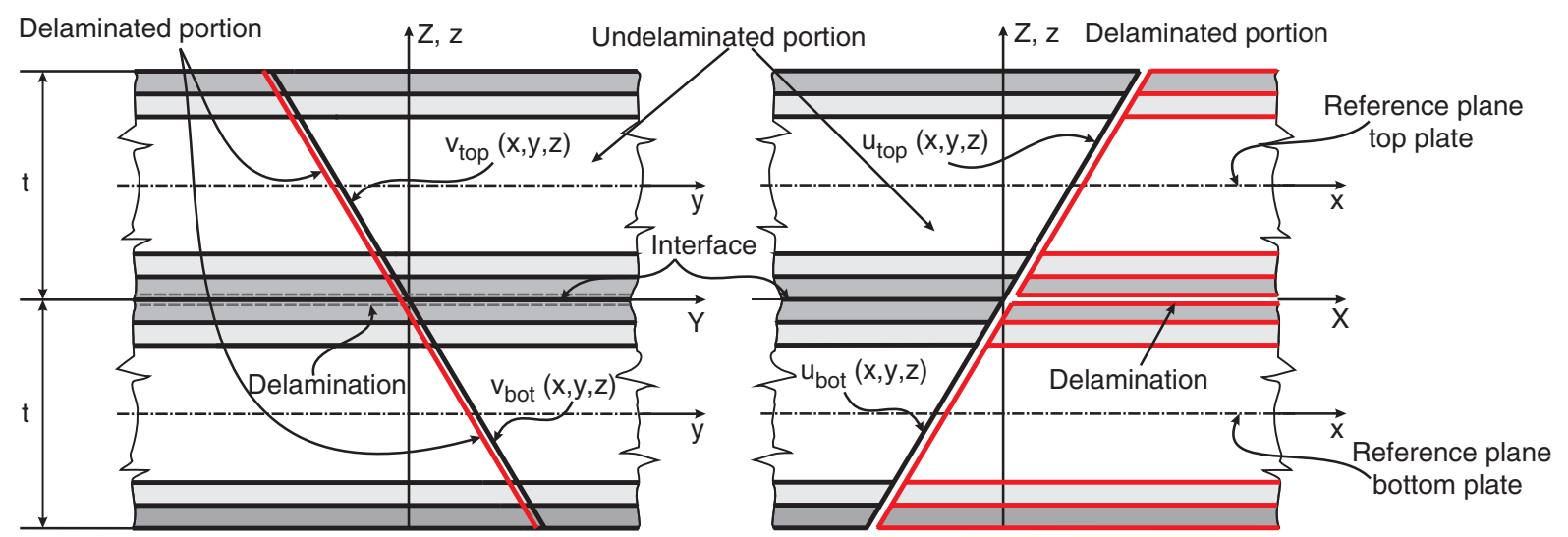

Figure I. Deformations of the top and bottom plate elements. 
These conditions make it possible to express $u_{0}$ and $v_{0}$ in terms of the rotation parameters:

$$
u_{0}=\frac{t}{2} \theta_{\mathrm{x}}, v_{0}=\frac{t}{2} \theta_{\mathrm{y}}
$$

Taking these back into equation (1), we obtain the displacement field satisfying the interface constraint conditions:

$$
u_{\text {top }}(x, y, z)=\theta_{\mathrm{x}}\left(\frac{t}{2}+z\right), v_{\text {top }}(x, y, z)=\theta_{\mathrm{y}}\left(\frac{t}{2}+z\right)
$$

For the bottom plate, similar expressions can be derived. Due to the symmetric lay-up with respect to the $x-y$ plane, we analyze only the top plate in the sequel. Based on equation (6), the strains and shear strains become:

$$
\left\{\begin{array}{c}
\varepsilon_{\mathrm{x}}^{(1)} \\
\varepsilon_{\mathrm{y}}^{(1)} \\
\gamma_{\mathrm{xy}}^{(1)}
\end{array}\right\}=\left\{\begin{array}{c}
\frac{\partial \theta_{\mathrm{x}}}{\partial x} \\
\frac{\partial \theta_{\mathrm{y}}}{\partial x} \\
\frac{\partial \theta_{\mathrm{x}}}{\partial y}+\frac{\partial \theta_{\mathrm{y}}}{\partial x}
\end{array}\right\},\left\{\begin{array}{c}
\varepsilon_{\mathrm{x}}^{(0)} \\
\varepsilon_{\mathrm{y}}^{(0)} \\
\gamma_{\mathrm{xy}}^{(0)}
\end{array}\right\}
$$

In this case, the system of equilibrium equations consists of three equations only:

$$
\begin{gathered}
\frac{\partial M_{\mathrm{x}}}{\partial x}+\frac{\partial M_{\mathrm{xy}}}{\partial y}+\frac{t}{2}\left(\frac{\partial N_{\mathrm{x}}}{\partial x}+\frac{\partial N_{\mathrm{xy}}}{\partial y}\right)-Q_{\mathrm{x}}=0, \\
\frac{\partial M_{\mathrm{xy}}}{\partial x}+\frac{\partial M_{\mathrm{y}}}{\partial y}+\frac{t}{2}\left(\frac{\partial N_{\mathrm{xy}}}{\partial x}+\frac{\partial N_{\mathrm{y}}}{\partial y}\right)-Q_{\mathrm{y}}=0, \\
\frac{\partial Q_{\mathrm{x}}}{\partial x}+\frac{\partial Q_{\mathrm{y}}}{\partial y}+q=0
\end{gathered}
$$

Calculating the stress resultants (equation (2)) in terms of the displacement parameters and taking them back into the equilibrium equations (equations (18)(20)), the following system of equations is obtained:

$$
\begin{gathered}
\hat{a}_{1} \frac{\partial^{2} \theta_{\mathrm{x}}}{\partial x^{2}}+\hat{a}_{2} \frac{\partial^{2} \theta_{\mathrm{x}}}{\partial y^{2}}+\hat{a}_{3} \theta_{\mathrm{x}}+\hat{a}_{4} \frac{\partial^{2} \theta_{\mathrm{y}}}{\partial x \partial y}+\hat{a}_{5} \frac{\partial w}{\partial x}=0, \\
\hat{b}_{1} \frac{\partial^{2} \theta_{\mathrm{x}}}{\partial x \partial y}+\hat{b}_{2} \frac{\partial^{2} \theta_{\mathrm{y}}}{\partial x^{2}}+\hat{b}_{3} \frac{\partial^{2} \theta_{\mathrm{y}}}{\partial y^{2}}+\hat{b}_{4} \theta_{\mathrm{y}}+\hat{b}_{5} \frac{\partial w}{\partial y}=0, \\
\hat{c}_{1} \frac{\partial \theta_{\mathrm{x}}}{\partial x}+\hat{c}_{2} \frac{\partial \theta_{\mathrm{y}}}{\partial y}+\hat{c}_{3} \frac{\partial^{2} w}{\partial x^{2}}+\hat{c}_{4} \frac{\partial^{2} w}{\partial y^{2}}+\hat{c}_{5} q=0
\end{gathered}
$$

where the coefficients depend on the stiffness parameters and the thickness of the plate, and are collected in Appendix 1. It is important to highlight that the reference planes of the top and bottom plates of the uncracked portion are the local midplanes (see Figure 1), and consequently the stiffness parameters in equation (4) for the delaminated and uncracked plate portions are the same. The different deformations of the two portions are included through the interface constraint conditions in equation (14).

\section{CLPT - Kirchhoff plate theory}

The Kirchhoff plate theory (CLPT) can be considered as a special case of FSDT, when the rotations become: ${ }^{2}$

$$
\theta_{\mathrm{x}}=-\frac{\partial w}{\partial x}, \theta_{\mathrm{y}}=-\frac{\partial w}{\partial y}
$$

i.e., in accordance with the Kirchhoff hypothesis, the normal of the cross section is parallel to the derivative of the deflection.

\section{Delaminated portion}

For the delaminated portion, the constant strains are the same as those in equation (6), the linear strains are

$$
\left\{\begin{array}{c}
\varepsilon_{\mathrm{x}}^{(1)} \\
\varepsilon_{\mathrm{y}}^{(1)} \\
\gamma \mathrm{xy}^{(1)}
\end{array}\right\}=\left\{\begin{array}{lll}
-\frac{\partial^{2} w}{\partial x^{2}} & -\frac{\partial^{2} w}{\partial y^{2}} & -2 \frac{\partial^{2} w}{\partial x \partial y}
\end{array}\right\}^{T}
$$

The shear strains $\gamma_{\mathrm{xz}}$ and $\gamma_{\mathrm{yz}}$ are apparently zero. The resulting equilibrium equations are given by equation (7); moreover, the three equations in equation (8) reduce to the one below:

$$
\frac{\partial^{2} M_{\mathrm{x}}}{\partial x^{2}}+2 \frac{\partial^{2} M_{\mathrm{xy}}}{\partial x \partial y}+\frac{\partial^{2} M_{\mathrm{y}}}{\partial y^{2}}=-q
$$

Taking the displacement parameters back into equations (6) and (26) we obtain:

$$
D_{11} \frac{\partial^{4} w}{\partial x^{4}}+2\left(D_{12}+D_{66}\right) \frac{\partial^{4} w}{\partial x^{2} \partial y^{2}}+D_{22} \frac{\partial^{4} w}{\partial y^{4}}=q
$$

Along with equations (9) and (10) (these still hold in the case of CLPT) in this case, we have a three-parameter displacement field, while the system consists of three PDEs. 


\section{Undelaminated portion}

The substitution of equation (24) into equation (16) yields the following displacement field for the undelaminated portion:

$u_{\mathrm{top}}(x, y, z)=-\frac{\partial w}{\partial x}\left(\frac{t}{2}+z\right), v_{\mathrm{top}}(x, y, z)=-\frac{\partial w}{\partial y}\left(\frac{t}{2}+z\right)$

In this case, the strain field can be obtained by equation (25) and the second of (17), and consequently the displacement field involves a single parameter, the deflection of the plate, $w(x, y)$. The equilibrium equations by equations (18)-(20) reduce to a single equation:

$$
\begin{aligned}
& \frac{\partial^{2} M_{\mathrm{x}}}{\partial x^{2}}+2 \frac{\partial^{2} M_{\mathrm{xy}}}{\partial x \partial y}+\frac{\partial^{2} M_{\mathrm{y}}}{\partial y^{2}}+\frac{t}{2}\left(\frac{\partial^{2} N_{\mathrm{x}}}{\partial x^{2}}+2 \frac{\partial^{2} N_{\mathrm{xy}}}{\partial x \partial y}+\frac{\partial^{2} N_{\mathrm{y}}}{\partial y^{2}}\right) \\
& \quad=-q
\end{aligned}
$$

Finally, by calculating the stress resultants from equations (2) and (3) we obtain the governing PDE of the deflection of undelaminated portion:

$$
\begin{gathered}
\left(D_{11}+\frac{A_{11} t^{2}}{4}\right) \frac{\partial^{4} w}{\partial x^{4}}+2\left(D_{12}+D_{66}+\frac{\left(A_{12}+A_{66}\right) t^{2}}{4}\right) \\
\frac{\partial^{4} w}{\partial x^{2} \partial y^{2}}+\left(D_{22}+\frac{A_{22} t^{2}}{4}\right) \frac{\partial^{4} w}{\partial y^{4}}=q
\end{gathered}
$$

As it can be seen from equation (30), the transformation of the local bending stiffness is involved with $t / 2$ distance from the local reference plane. ${ }^{1}$ In the next section, we solve a simply-supported plate subjected to a point force by the state-space model. ${ }^{2}$ The displacement and stress fields are calculated and the $J$-integral is utilized to calculate the ERR distributions along the delamination front.

\section{Example - simply-supported plate, Lévy plate formulation}

In this section, we apply the state-space model $^{2}$ to solve the system of equations for a delaminated plate subjected to a point force, shown in Figure 2. The governing PDE system is different for the delaminated and uncracked parts; therefore, the state-space models are developed separately. In accordance with Lévy plate formulation, the displacement components and the external load for simply-supported (Mindlin and Kirchhoff) plates ${ }^{1-3}$ can be written as:

$\left\{\begin{array}{c}u_{0}(x, y) \\ v_{0}(x, y) \\ \theta_{\mathrm{x}}(x, y) \\ \theta_{\mathrm{y}}(x, y) \\ w(x, y)\end{array}\right\}=\sum_{n=1}^{\infty}\left\{\begin{array}{c}U_{0 \mathrm{n}}(x) \sin \beta y \\ V_{0 \mathrm{n}}(x) \cos \beta y \\ X_{\mathrm{n}}(x) \sin \beta y \\ Y_{\mathrm{n}}(x) \cos \beta y \\ W_{\mathrm{n}}(x) \sin \beta y\end{array}\right\}, q=\sum_{n=1}^{\infty} Q_{\mathrm{n}} \sin \beta y$

where $\beta=n \pi / b$. Apparently, in the case of Kirchhoff plate theory $\theta_{\mathrm{x}}$ and $\theta_{\mathrm{y}}$ are not applicable.

\section{FSDT-Mindlin plate theory}

Delaminated portion. Taking the solutions above back into the system of governing equations of the delaminated portion (equations (9)-(13)), we can derive the state-space model, in a general form it becomes:

$$
{\underline{Z^{\prime}}}^{(d)}=\underline{T}^{(d)} \underline{Z}^{(d)}+\underline{F}^{(d)}
$$

where the superscript "( $d)$ " refers to the delaminated plate portion and $\underline{Z}$ is the state vector:

$$
\underline{Z}^{(d)}=\left[\begin{array}{llllllllll}
U_{0 n} & U_{0 n}^{\prime} & V_{0 n} & V_{0 n}^{\prime} & X_{n} & X_{n}^{\prime} & Y_{n} & Y_{n}^{\prime} & W_{n} & W_{n}^{\prime}
\end{array}\right]^{T}
$$

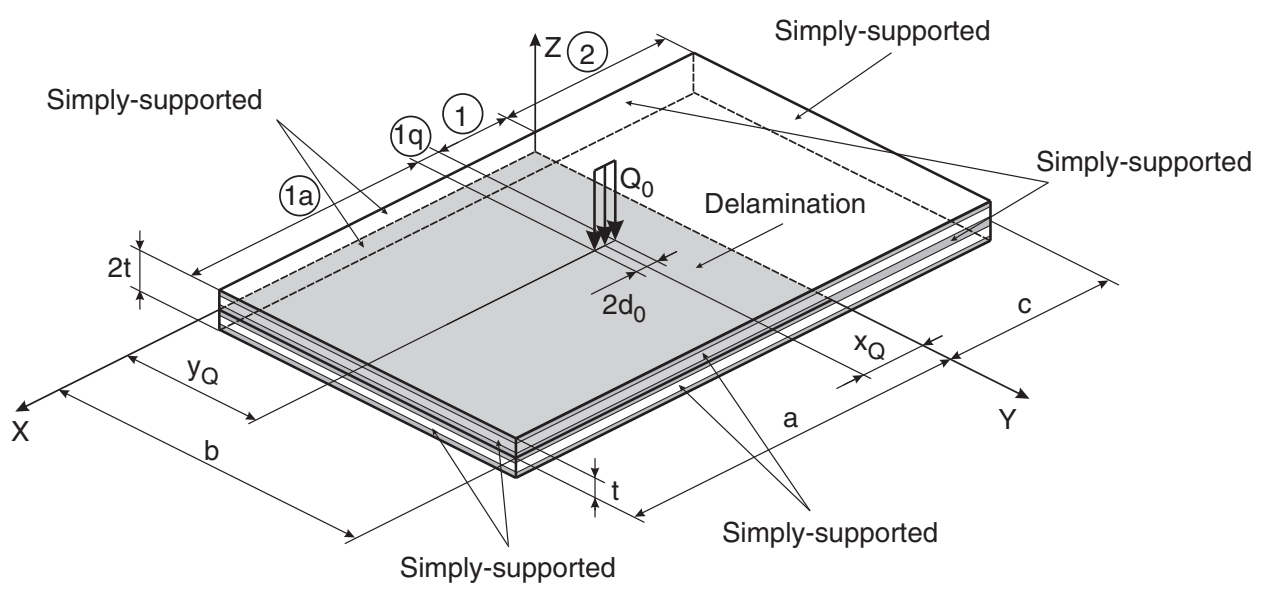

Figure 2. Simply-supported plate subjected to point force. 
moreover, $\underline{T}$ is the system matrix, $F$ contains the inhomogeneity of the governing $\mathrm{PDE}^{-}$system. In an expanded form equation (32) becomes:
The expanded state-space model becomes:

$$
\left[\begin{array}{c}
U_{0 \mathrm{n}}^{\prime} \\
U_{0 \mathrm{n}}^{\prime \prime} \\
V_{0 \mathrm{n}}^{\prime} \\
V_{0 \mathrm{n}}^{\prime \prime} \\
X_{\mathrm{n}}^{\prime} \\
X_{\mathrm{n}}^{\prime \prime} \\
Y_{\mathrm{n}}^{\prime} \\
Y_{\mathrm{n}}^{\prime \prime} \\
W_{\mathrm{n}}^{\prime} \\
W_{\mathrm{n}}^{\prime \prime}
\end{array}\right]=\left[\begin{array}{cccccccccc}
0 & 1 & 0 & 0 & 0 & 0 & 0 & 0 & 0 & 0 \\
f_{1} & 0 & 0 & f_{2} & 0 & 0 & 0 & 0 & 0 & 0 \\
0 & 0 & 0 & 1 & 0 & 0 & 0 & 0 & 0 & 0 \\
0 & g_{1} & g_{2} & 0 & 0 & 0 & 0 & 0 & 0 & 0 \\
0 & 0 & 0 & 0 & 0 & 1 & 0 & 0 & 0 & 0 \\
0 & 0 & 0 & 0 & h_{1} & 0 & 0 & h_{2} & 0 & h_{3} \\
0 & 0 & 0 & 0 & 0 & 0 & 0 & 1 & 0 & 0 \\
0 & 0 & 0 & 0 & 0 & j_{1} & j_{2} & 0 & j_{3} & 0 \\
0 & 0 & 0 & 0 & 0 & 0 & 0 & 0 & 0 & 1 \\
0 & 0 & 0 & 0 & 0 & k_{1} & k_{2} & 0 & k_{3} & 0
\end{array}\right]\left[\begin{array}{c}
U_{0 \mathrm{n}} \\
U_{0 \mathrm{n}}^{\prime} \\
V_{0 \mathrm{n}} \\
V_{0 \mathrm{n}}^{\prime} \\
X_{\mathrm{n}} \\
X_{\mathrm{n}}^{\prime} \\
Y_{\mathrm{n}} \\
Y_{\mathrm{n}}^{\prime} \\
W_{\mathrm{n}} \\
W_{\mathrm{n}}^{\prime}
\end{array}\right]+\left[\begin{array}{c}
0 \\
0 \\
0 \\
0 \\
0 \\
0 \\
0 \\
0 \\
0 \\
k_{4} Q_{\mathrm{n}}
\end{array}\right]
$$

where the coefficients in the $10 \times 10$ system matrix $\underline{\underline{T}}$ are collected in Appendix 2. The general solution of equation (32) is ${ }^{2}$

$$
\begin{gathered}
\underline{Z}^{(d)}(x)=e^{\underline{\underline{T}}^{(d)} x}\left[\underline{K}^{(d)}+\int_{x_{0}}^{x} e^{-\underline{\underline{T}}^{(d)} \xi} \underline{F}^{(d)}(\xi) \mathrm{d} \xi\right] \\
=\underline{G}^{(d)}(x) \underline{\underline{K}}^{(d)}+\underline{H}^{(d)}(x)
\end{gathered}
$$

where $K$ is the vector of constants, $H$ is the vector of particular solutions.

Uncracked portion. It has been shown that because of the kinematic constraints, two of the five displacement parameters can be eliminated. Utilizing equations (21)-(23), the state-space model can be derived as:

$$
{\underline{Z^{\prime}}}^{(u d)}=\underline{\underline{T}}^{(u d)} \underline{Z}^{(u d)}+\underline{F}^{(u d)}
$$

where the superscript " $(u d)$ " refers to the undelaminated region. The state vector in this case is

$$
\underline{Z}^{(u d)}=\left[\begin{array}{llllll}
X_{\mathrm{n}} & X_{\mathrm{n}}^{\prime} & Y_{\mathrm{n}} & Y_{\mathrm{n}}^{\prime} & W_{\mathrm{n}} & W_{\mathrm{n}}^{\prime}
\end{array}\right]^{T}
$$

$$
\left[\begin{array}{c}
X_{\mathrm{n}}^{\prime} \\
X_{\mathrm{n}}^{\prime \prime} \\
Y_{\mathrm{n}}^{\prime} \\
Y_{\mathrm{n}}^{\prime \prime} \\
W_{\mathrm{n}}^{\prime} \\
W_{\mathrm{n}}^{\prime \prime}
\end{array}\right]=\left[\begin{array}{cccccc}
0 & 1 & 0 & 0 & 0 & 0 \\
\hat{d}_{1} & 0 & 0 & \hat{d}_{2} & 0 & \hat{d}_{3} \\
0 & 0 & 0 & 1 & 0 & 0 \\
0 & \hat{e}_{1} & \hat{e}_{2} & 0 & \hat{e}_{3} & 0 \\
0 & 0 & 0 & 0 & 0 & 1 \\
0 & \hat{f}_{1} & \hat{f}_{2} & 0 & \hat{f}_{3} & 0
\end{array}\right]\left[\begin{array}{c}
X_{\mathrm{n}} \\
X_{\mathrm{n}}^{\prime} \\
Y_{\mathrm{n}} \\
Y_{\mathrm{n}}^{\prime} \\
W_{\mathrm{n}} \\
W_{\mathrm{n}}^{\prime}
\end{array}\right]+\left[\begin{array}{c}
0 \\
0 \\
0 \\
0 \\
0 \\
\hat{f}_{4} Q_{\mathrm{n}}
\end{array}\right]
$$

which involves a $6 \times 6$ system matrix with coefficients defined in Appendix 1. Considering the fact that there is no external load at the uncracked plate portion the solution of equation (38) is

$$
\underline{Z}^{(u d)}(x)=e^{\underline{\underline{T}}^{(u d)} x} \underline{K}^{(u d)}=\underline{\underline{G}}^{(u d)}(x) \underline{K}^{(u d)}
$$

\section{Kirchhoff plate theory}

Delaminated portion. In this case, the system matrix is an $8 \times 8$ matrix. Without going into details, based on equations (9), (10) and (27), the state-space model takes the form of:

$$
\left[\begin{array}{c}
U_{0 \mathrm{n}}^{\prime} \\
U_{0 \mathrm{n}}^{\prime \prime} \\
V_{0 \mathrm{n}}^{\prime} \\
V_{0 \mathrm{n}}^{\prime \prime} \\
W_{\mathrm{n}}^{\prime} \\
W_{\mathrm{n}}^{\prime \prime} \\
W_{\mathrm{n}}^{\prime \prime \prime} \\
W_{\mathrm{n}}^{I V}
\end{array}\right]=\left[\begin{array}{cccccccc}
0 & 1 & 0 & 0 & 0 & 0 & 0 & 0 \\
f_{1} & 0 & 0 & f_{2} & 0 & 0 & 0 & 0 \\
0 & 0 & 0 & 1 & 0 & 0 & 0 & 0 \\
0 & g_{1} & g_{2} & 0 & 0 & 0 & 0 & 0 \\
0 & 0 & 0 & 0 & 0 & 1 & 0 & 0 \\
0 & 0 & 0 & 0 & 0 & 0 & 1 & 0 \\
0 & 0 & 0 & 0 & 0 & 0 & 0 & 1 \\
0 & 0 & 0 & 0 & -\beta^{4} \frac{d_{3}}{c_{1}} & 0 & 2 \beta^{2} \frac{c_{4}}{c_{1}} & 0
\end{array}\right]\left[\begin{array}{c}
U_{0 \mathrm{n}} \\
U_{0 \mathrm{n}}^{\prime} \\
V_{0 \mathrm{n}} \\
V_{0 \mathrm{n}}^{\prime} \\
W_{\mathrm{n}} \\
W_{\mathrm{n}}^{\prime} \\
W_{\mathrm{n}}^{\prime \prime} \\
W_{\mathrm{n}}^{\prime \prime \prime}
\end{array}\right]+\left[\begin{array}{c}
0 \\
0 \\
0 \\
0 \\
0 \\
0 \\
0 \\
Q_{\mathrm{n}} \\
c_{1}
\end{array}\right]
$$

where the coefficients are defined in Appendix 2. 
Undelaminated portion. From equations (30) and (31), we obtain the following state-space model:

$$
\left[\begin{array}{c}
W_{\mathrm{n}}^{\prime} \\
W_{\mathrm{n}}^{\prime \prime} \\
W_{\mathrm{n}}^{\prime \prime} \\
W_{\mathrm{n}}^{I V}
\end{array}\right]=\left[\begin{array}{cccc}
0 & 1 & 0 & 0 \\
0 & 0 & 1 & 0 \\
0 & 0 & 0 & 1 \\
-\beta^{4} \frac{\hat{b}_{3}}{\hat{a}_{1}} & 0 & 2 \beta^{2} \frac{\hat{a}_{4}}{\hat{a}_{1}} & 0
\end{array}\right]\left[\begin{array}{c}
W_{\mathrm{n}} \\
W_{\mathrm{n}}^{\prime} \\
W_{\mathrm{n}}^{\prime \prime} \\
W_{\mathrm{n}}^{\prime \prime \prime}
\end{array}\right]+\left[\begin{array}{c}
0 \\
0 \\
0 \\
\frac{1}{\hat{a}_{1}} Q_{\mathrm{n}}
\end{array}\right]
$$

where the coefficients are defined in Appendix 1.

\section{Boundary and continuity conditions}

The elements of the state vectors in equations (36) and (41) can be referred to as:

$$
Z_{\mathrm{i}}^{(d)}=\sum_{\mathrm{j}} G_{\mathrm{ij}}^{(d)} K_{\mathrm{j}}^{(d)}+H_{\mathrm{j}}^{(d)}, Z_{\mathrm{i}}^{(u d)}=\sum_{\mathrm{j}} G_{\mathrm{ij}}^{(u d)} K_{\mathrm{j}}^{(u d)}+H_{\mathrm{j}}^{(u d)}
$$

In accordance with Figure 2, we have four different plate portions. The point force causes singularity in the PDEs, therefore a plate portion loaded by a constant line force was applied, the length $d_{0}$ was a very small value compared to the plate dimensions. In this case, $Q_{\mathrm{n}}=2 q_{0} / b \cdot \sin \left(\beta y_{0}\right)$ [2]. Thus, the four parts are denoted by "1a", "1q", "1" for the delaminated portion and " 2 " for the undelaminated region. Consequently, the state-space models for the delaminated portion are utilized for the "1a", "1q" and "1" portions, while the model for the undelaminated portion was used to capture region " 2 ". The boundary conditions (B.C.s) are formulated through the displacement parameters and the stress resultants. The latter ones can be expressed in the following forms:

$\left\{\begin{array}{c}N_{\mathrm{x}} \\ N_{\mathrm{y}} \\ M_{\mathrm{x}} \\ M_{\mathrm{y}} \\ Q_{\mathrm{x}}\end{array}\right\}=\sum_{n=1}^{\infty}\left\{\begin{array}{c}n_{\mathrm{xn}} \\ n_{\mathrm{yn}} \\ m_{\mathrm{xn}} \\ m_{\mathrm{yn}} \\ q_{\mathrm{xn}}\end{array}\right\} \sin \beta y,\left\{\begin{array}{c}N_{\mathrm{xy}} \\ M_{\mathrm{xy}} \\ Q_{\mathrm{y}}\end{array}\right\}=\sum_{n=1}^{\infty}\left\{\begin{array}{c}n_{\mathrm{xyn}} \\ m_{\mathrm{xyn}} \\ q_{\mathrm{yn}}\end{array}\right\} \cos \beta y$

i.e. $n_{\mathrm{xn}}$ is the function coefficient in the Fourier series of $N_{\mathrm{x}}$, etc. To define the B.C.s we start with CLPT, and then by highlighting the differences between the two theories we continue with FSDT.

Kirchhoff plate theory. For the present problem, 28 conditions need to be formulated. The B.C.s for simplysupported edges are (6 conditions)

$$
\begin{aligned}
W_{\mathrm{n}}^{(1 a)}(a) & =0, V_{0 \mathrm{n}}^{(1 a)}(a)=0, n_{\mathrm{xn}}^{(1 a)}(a)=0, m_{\mathrm{xn}}^{(1 a)}(a)=0 \\
W_{\mathrm{n}}^{(2)}(-c) & =0, m_{\mathrm{xn}}^{(2)}(-c)+\frac{t}{2} n_{\mathrm{xn}}^{(2)}(-c)=0
\end{aligned}
$$

The continuity conditions between regions " 1 " and "2" are (6 conditions)

$$
\begin{aligned}
U_{0 \mathrm{n}}^{(1)}(0) & =-\frac{t}{2} W_{\mathrm{n}}^{\prime(2)}(0), V_{0 \mathrm{n}}^{(1)}(0)=-\frac{t}{2} \beta W_{\mathrm{n}}^{(2)}(0) \\
W_{\mathrm{n}}^{(1)}(0) & =W_{n}^{(2)}(0), W_{\mathrm{n}}^{(1)}(0)=W_{\mathrm{n}}^{\prime(2)}(0) \\
m_{\mathrm{xn}}^{(1)}(0) & =m_{\mathrm{xn}}^{(2)}(0)+\frac{t}{2} n_{\mathrm{xn}}^{(2)}(0) \\
q_{\mathrm{xn}}^{(1)}(0)-\beta m_{\mathrm{xyn}}^{(1)}(0)= & m_{x n}^{(2)}(0)+\frac{t}{2} n_{\mathrm{xn}}^{\prime(2)}(0) \\
& -2 \beta\left(m_{\mathrm{xyn}}^{(2)}(0)+\frac{t}{2} n_{\mathrm{xyn}}^{(2)}(0)\right)
\end{aligned}
$$

The continuity and boundary conditions for the $M_{\mathrm{x}}$ bending moment and $V_{\mathrm{x}}=Q_{\mathrm{x}}+\partial M_{\mathrm{xy}} / \partial \mathrm{y}$ (effective or Kirchhoff shear force ${ }^{3}$ ), respectively, must consider the fact that the in-plane normal and shear forces produce concentrated moments about the global $X$ and $Y$ axes of the uncracked plate portion. This effect - which is included also in equations (18) and (19) - is demonstrated in Figure 3 and was considered in the continuity conditions. Thus, the continuity conditions between regions " $1 \mathrm{q}$ " and " 1 " are (8 conditions)

$$
\begin{aligned}
U_{0 \mathrm{n}}^{(1 q)}\left(x_{01}\right)= & U_{0 \mathrm{n}}^{(1)}\left(x_{01}\right), V_{0 \mathrm{n}}^{(1 q)}(0)=V_{0 \mathrm{n}}^{(1)}(0), \\
W_{\mathrm{n}}^{(1 q)}\left(x_{01}\right)= & W_{\mathrm{n}}^{(1)}\left(x_{01}\right), \\
W_{\mathrm{n}}^{(1 q)}\left(x_{01}\right)= & W_{\mathrm{n}}^{(1)}\left(x_{01}\right), n_{\mathrm{xn}}^{(1 q)}\left(x_{01}\right)=n_{\mathrm{xn}}^{(1)}\left(x_{01}\right), \\
& n_{\mathrm{xyn}}^{(1 q)}\left(x_{01}\right)=n_{\mathrm{xyn}}^{(1)}\left(x_{01}\right), \\
m_{\mathrm{xn}}^{(1 q)}\left(x_{01}\right)= & m_{\mathrm{xn}}^{(1)}\left(x_{01}\right), q_{\mathrm{xn}}^{(1)}\left(x_{01}\right)-\beta m_{\mathrm{xyn}}^{(1 q)}\left(x_{01}\right) \\
= & q_{\mathrm{xn}}^{(1)}\left(x_{01}\right)-\beta m_{\mathrm{xyn}}^{(1)}\left(x_{01}\right),
\end{aligned}
$$
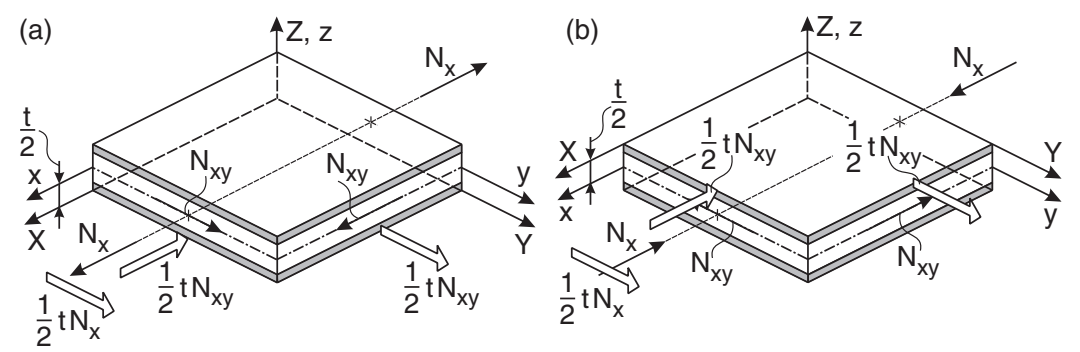

Figure 3. The effect of in-plane normal and shear forces of the top (a) and bottom (b) plates on the global moment equilibrium of the system. 
where $x_{01}=x_{\mathrm{Q}}-d_{0}$. Moreover, 8 continuity conditions can be formulated between regions " $1 \mathrm{a}$ " and " $1 \mathrm{q}$ " at $x_{02}=x_{\mathrm{Q}}+d_{0}$, these are similar to those in equation (46), therefore they are not presented. Totally, the system involves 28 equations and the same number of unknowns.

Mindlin plate theory. The B.C.s given by equation (44) are complemented with further two conditions (resulting in 8 conditions):

$$
Y_{\mathrm{n}}^{(1 a)}(a)=0, \quad V_{0 \mathrm{n}}^{(2)}(a)=0
$$

The continuity conditions between regions " 1 " and "2" are (8 conditions):

$$
\begin{aligned}
& U_{0 \mathrm{n}}^{(1)}(0)=\frac{t}{2} X_{\mathrm{n}}^{(2)}(0), X_{\mathrm{n}}^{(1)}(0)=X_{\mathrm{n}}^{(2)}(0), V_{0 \mathrm{n}}^{(1)}(0)=\frac{t}{2} Y_{\mathrm{n}}^{(2)}(0), \\
& Y_{\mathrm{n}}^{(1)}(0)=Y_{\mathrm{n}}^{(2)}(0), W_{\mathrm{n}}^{(1)}(0)=W_{\mathrm{n}}^{(2)}(0), W_{\mathrm{n}}^{\prime}(1)(0)=W_{\mathrm{n}}^{\prime}(2)(0), \\
& m_{\mathrm{xn}}^{(1)}(0)=m_{\mathrm{xn}}^{(2)}(0)+\frac{t}{2} n_{\mathrm{xn}}^{(2)}(0), m_{\mathrm{xyn}}^{(1)}(0)=m_{\mathrm{xyn}}^{(2)}(0)+\frac{t}{2} n_{\mathrm{xyn}}^{(2)}(0)
\end{aligned}
$$

The latter two ones consider the effect presented in Figure 4. The continuity conditions between regions "1q" and " $1 "$ are (10 conditions)

$$
\begin{aligned}
U_{0 \mathrm{n}}^{(1 q)}\left(x_{01}\right) & =U_{0 \mathrm{n}}^{(1)}\left(x_{01}\right), X_{\mathrm{n}}^{(1 q)}\left(x_{01}\right)=X_{\mathrm{n}}^{(1)}\left(x_{01}\right), \\
V_{0 \mathrm{n}}^{(1 q)}\left(x_{01}\right) & =V_{0 \mathrm{n}}^{(1)}\left(x_{01}\right) \\
Y_{\mathrm{n}}^{(1 q)}\left(x_{01}\right) & =Y_{\mathrm{n}}^{(1)}\left(x_{01}\right), W_{\mathrm{n}}^{(1 q)}\left(x_{01}\right)=W_{\mathrm{n}}^{(1)}\left(x_{01}\right), \\
W_{\mathrm{n}}^{(1 q)}\left(x_{01}\right) & =W_{\mathrm{n}}^{(1)}\left(x_{01}\right) \\
n_{\mathrm{xn}}^{(1 q)}\left(x_{01}\right) & =n_{\mathrm{xn}}^{(1)}\left(x_{01}\right), n_{\mathrm{xyn}}^{(1 q)}\left(x_{01}\right)=n_{\mathrm{xyn}}^{(1)}\left(x_{01}\right), \\
m_{\mathrm{xn}}^{(1 q)}\left(x_{01}\right) & =m_{\mathrm{xn}}^{(1)}\left(x_{01}\right), m_{\mathrm{xyn}}^{(1 q)}\left(x_{01}\right)=m_{\mathrm{xyn}}^{(1)}\left(x_{01}\right)
\end{aligned}
$$

Further, 10 continuity conditions can be formulated between regions " $1 \mathrm{a}$ " and " $1 \mathrm{q}$ " at $x_{02}=x_{\mathrm{Q}}+d_{0}$, and so totally the system involves 36 equations. Based on the continuity conditions, the shear forces $Q_{\mathrm{x}}, Q_{\mathrm{y}}$ are continuous across the delamination front.

\section{Calculation of the j-integral}

In the general $3 \mathrm{D}$ case, the $J$-integral is defined as: ${ }^{50,51}$

$$
J_{\mathrm{k}}=\int_{\mathrm{C}}\left(W n_{\mathrm{k}}-\sigma_{\mathrm{ij}} u_{\mathrm{i}, \mathrm{k}} n_{\mathrm{j}}\right) d s-\int_{\mathrm{A}}\left(\sigma_{\mathrm{i} 3} u_{\mathrm{i}, \mathrm{k}}\right)_{3} \mathrm{~d} A, k=1,2,3
$$

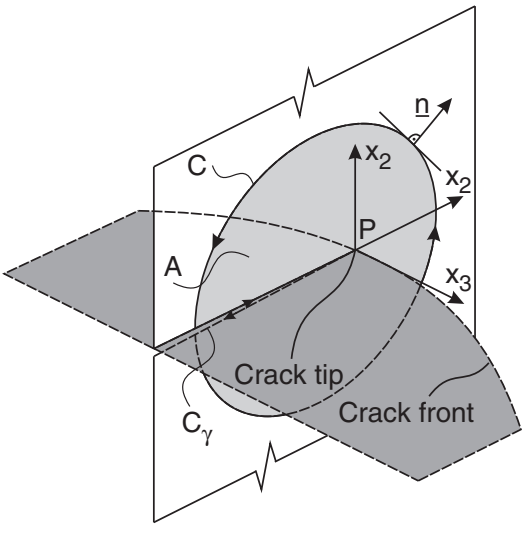

Figure 4. Reference system for the J-integral.

where $W$ is the strain energy density:

$W=\int_{0}^{\varepsilon_{i j}} \sigma_{\mathrm{ij}} \mathrm{d} \varepsilon_{\mathrm{ij}}=\frac{1}{2}\left(\sigma_{\mathrm{x}} \varepsilon_{\mathrm{x}}+\sigma_{\mathrm{y}} \varepsilon_{\mathrm{y}}+\tau_{\mathrm{xy}} \gamma_{\mathrm{xy}}+\tau_{\mathrm{xz}} \gamma_{\mathrm{xz}}+\tau_{\mathrm{yz}} \gamma_{\mathrm{yz}}\right)$

Moreover, based on Figure $4, n_{\mathrm{k}}$ is the outward normal vector of the contour $C, \sigma_{\mathrm{ij}}$ is the stress tensor, $u_{\mathrm{i}}$ is the displacement vector, $A$ is the area enclosed by the contour $C$. The separation of the modes is possible by using a direct method ${ }^{50,51}$ :

$$
J_{1}=J_{\mathrm{I}}+J_{\mathrm{II}}+J_{\mathrm{III}}, J_{2}=-2 \sqrt{J_{\mathrm{I}} J_{\mathrm{II}}}, J_{3}=J_{\mathrm{III}}
$$

In our problem, $x_{1}=x, x_{2}=z$ and $x_{3}=y$, respectively. For the calculation, we apply a zero-area path around the crack tip. ${ }^{36}$ This way the surface integral in equation (50) becomes zero. The layerwise stressstrain relations in laminated composite plates are $\mathrm{r}^{1,2}$

$$
\begin{aligned}
& {\left[\begin{array}{c}
\sigma_{\mathrm{x}} \\
\sigma_{\mathrm{x}} \\
\tau_{\mathrm{xy}}
\end{array}\right]^{(k)}=\left[\begin{array}{ccc}
\bar{C}_{11} & \bar{C}_{12} & 0 \\
\bar{C}_{21} & \bar{C}_{22} & 0 \\
0 & 0 & \bar{C}_{66}
\end{array}\right]^{(k)}\left[\begin{array}{c}
\varepsilon_{\mathrm{x}} \\
\varepsilon_{\mathrm{y}} \\
\gamma_{\mathrm{xy}}
\end{array}\right],} \\
& {\left[\begin{array}{c}
\tau_{\mathrm{xz}} \\
\tau_{\mathrm{yz}}
\end{array}\right]^{(k)}=\left[\begin{array}{cc}
\bar{C}_{55} & 0 \\
0 & \bar{C}_{44}
\end{array}\right]^{(k)}\left[\begin{array}{l}
\gamma_{\mathrm{xz}} \\
\gamma_{\mathrm{yz}}
\end{array}\right]}
\end{aligned}
$$

where $\left\{\bar{C}_{i j}\right\}$ is the stiffness matrix of the $k^{\text {th }}$ laminate. Taking the stresses and strains calculated by FSDT back into $J_{1}$ in equation (52), we obtain an expression 
including the product of stress resultants and strain components in the form of

$$
\begin{aligned}
J_{1}= & \frac{1}{2}\left(\left.N_{\mathrm{x} 1} \varepsilon_{\mathrm{x} 1}^{(0)}\right|_{\mathrm{x}=+0}-\left.N_{\mathrm{x} 2} \varepsilon_{\mathrm{x} 2}^{(0)}\right|_{\mathrm{x}=-0}\right) \\
& -\frac{1}{2}\left(\left.N_{\mathrm{y} 1} \varepsilon_{\mathrm{y} 1}^{(0)}\right|_{\mathrm{x}=+0}-\left.N_{\mathrm{y} 2} \varepsilon_{\mathrm{y} 2}^{(0)}\right|_{\mathrm{x}=-0}\right) \\
& +\frac{1}{2}\left(\left.M_{\mathrm{x} 1} \varepsilon_{\mathrm{x} 1}^{(1)}\right|_{\mathrm{x}=+0}-\left.M_{\mathrm{x} 2} \varepsilon_{\mathrm{x} 2}^{(1)}\right|_{\mathrm{x}=-0}\right) \\
& -\frac{1}{2}\left(\left.M_{\mathrm{y} 1} \varepsilon_{\mathrm{y} 1}^{(1)}\right|_{x=+0}-\left.M_{\mathrm{y} 2} \varepsilon_{\mathrm{y} 2}^{(1)}\right|_{x=-0}\right) \\
& -\frac{1}{2}\left(\left.N_{\mathrm{xy} 1} \hat{\gamma}_{\mathrm{x} y 1}^{(0)}\right|_{\mathrm{x}=+0}-\left.N_{\mathrm{xy} 2} \hat{\gamma}_{\mathrm{xy} 2}^{(0)}\right|_{\mathrm{x}=-0}\right) \\
& -\frac{1}{2}\left(\left.M_{\mathrm{xy} 1} \hat{\gamma}_{\mathrm{xy} 1}^{(1)}\right|_{\mathrm{x}=+0}-\left.M_{\mathrm{xy} 2} \hat{\gamma}_{\mathrm{xy} 2}^{(1)}\right|_{x=-0}\right) \\
& +\left.Q_{\mathrm{x} 1}\left(\frac{1}{2} \gamma_{\mathrm{xz} 1}^{(0)}-\frac{\partial w_{1}}{\partial x}\right)\right|_{\mathrm{x}=+0} \\
& -\left.Q_{\mathrm{x} 2}\left(\frac{1}{2} \gamma_{\mathrm{xz} 2}^{(0)}-\frac{\partial w_{2}}{\partial x}\right)\right|_{x=-0} \\
& +\frac{1}{2}\left(\left.Q_{\mathrm{y} 1} \gamma_{\mathrm{yz} 1}^{(0)}\right|_{\mathrm{x}=+0}-\left.Q_{\mathrm{y} 2} \gamma_{\mathrm{y} 22}^{(0)}\right|_{x=-0}\right)
\end{aligned}
$$

where e.g. $N_{\mathrm{x} 1}$ is the in-plane normal force for the delaminated portion, $\varepsilon_{x} 1^{(0)}$ is the constant part of the strain in the $x$ direction as it is defined in equation (6) etc. Moreover, the shear strains with the hat are

$$
\hat{\gamma}_{\mathrm{xy}}^{(0)}=\frac{\partial u_{0}}{\partial y}-\frac{\partial v_{0}}{\partial x}, \hat{\gamma}_{\mathrm{xy}}^{(1)}=\frac{\partial \theta_{\mathrm{x}}}{\partial y}-\frac{\partial \theta_{\mathrm{y}}}{\partial x}
$$

for the FSDT theory and

$$
\hat{\gamma}_{\mathrm{xy}}^{(0)}=\frac{\partial u_{0}}{\partial y}-\frac{\partial v_{0}}{\partial x}, \hat{\gamma}_{\mathrm{xy}}^{(1)}=0
$$

for the CLPT. The latter is not surprising after substituting equation (24) into equation (55). Considering the fact that $Q_{\mathrm{x}}, Q_{\mathrm{y}}$ and the corresponding strains are continuous across portions " 1 " and " 2 ", the relevant part of the $J$-integral vanishes. In the case of Kirchhoff plate theory, the corresponding terms are apparently zero. The remaining part can be separated based on the direct method (refer to equation (52)) or by simply separating the terms including the $\sin$ (mode-II) and $\cos$ (mode-III) functions, leading to

$$
\begin{aligned}
J_{I I}= & 2\left\{\frac{1}{2}\left(\left.N_{\mathrm{x} 1} \varepsilon_{\mathrm{x} 1}^{(0)}\right|_{\mathrm{x}=+0}-\left.N_{\mathrm{x} 2} \varepsilon_{\mathrm{x} 2}^{(0)}\right|_{\mathrm{x}=-0}\right)\right. \\
& -\frac{1}{2}\left(\left.N_{\mathrm{y} 1} \varepsilon_{y 1}^{(0)}\right|_{\mathrm{x}=+0}-\left.N_{\mathrm{y} 2} \varepsilon_{\mathrm{y} 2}^{(0)}\right|_{\mathrm{x}=-0}\right) \\
& +\frac{1}{2}\left(\left.M_{\mathrm{x} 1} \varepsilon_{\mathrm{x} 1}^{(1)}\right|_{\mathrm{x}=+0}-\left.M_{\mathrm{x} 2} \varepsilon_{\mathrm{x} 2}^{(1)}\right|_{\mathrm{x}=-0}\right) \\
& \left.-\frac{1}{2}\left(\left.M_{\mathrm{y} 1} \varepsilon_{\mathrm{y} 1}^{(1)}\right|_{\mathrm{x}=+0}-\left.M_{\mathrm{y} 2} \varepsilon_{\mathrm{y} 2}^{(1)}\right|_{\mathrm{x}=-0}\right)\right\}
\end{aligned}
$$

$$
\begin{aligned}
J_{I I I}= & 2\left\{-\frac{1}{2}\left(\left.N_{x y 1} \hat{\gamma}_{x y 1}^{(0)}\right|_{x=+0}-\left.N_{x y 2} \hat{\gamma}_{x y 2}^{(0)}\right|_{x=-0}\right)\right. \\
& \left.-\frac{1}{2}\left(\left.M_{x y 1} \hat{\gamma}_{x y 1}^{(1)}\right|_{x=+0}-\left.M_{x y 2} \hat{\gamma}_{x y 2}^{(1)}\right|_{x=-0}\right)\right\}
\end{aligned}
$$

which is valid for both theories. The production by 2 is necessary because we have top and bottom plates and only the top plate was analyzed. For the CLPT, the stress resultants are calculated by the first of equation (2), the strains are calculated by equations (6), (25) and from the second of (17). In the case of FSDT, the stress resultants are obtained from equation (2), the strains are determined from equations (6) and (17). Also, the present formulation does not incorporate any physically inconsistent parameters (e.g. shear compliances, see e.g. $[8,41,45,46])$, it is based on an entirely exact formulation including the material law of orthotropic solids.

\section{Results and discussion}

The properties of the analyzed simply-supported plate were (refer to Figure 3): $a=105 \mathrm{~mm}$ (crack length), $c=45 \mathrm{~mm}$ (uncracked length), $b=100 \mathrm{~mm}$ (plate width), $t=2 \mathrm{~mm}$ (half plate thickness), $Q_{0}=1000 \mathrm{~N}$ (point force magnitude), $x_{\mathrm{Q}}=31 \mathrm{~mm}, y_{\mathrm{Q}}=50 \mathrm{~mm}$ (point of action coordinates of $Q_{0}$ ), $d_{0}=0.1 \mathrm{~mm}$ and $q_{0}=Q_{0} / 2 d_{0}$. The plate is made of a carbon/epoxy material, the lay-up of the plate was $\left[ \pm 45_{2}^{\mathrm{f}}\right.$; $\left.0_{12} ; \pm 45_{2}^{\mathrm{f}}\right]$ for the delaminated and $\left[ \pm 45_{2}^{\mathrm{f}} ; 0_{12} ; \pm 45_{2}^{\mathrm{f}}\right]_{\mathrm{s}}$ for the uncracked part. The superscript " $\mathrm{f}$ " refers to the fact that the cross-ply laminate is a woven fabric panel. The properties of the individual laminae are given in Table $1 .{ }^{1}$ The computation was performed in the code MAPLE $12^{52}$ in accordance with the following points. The stiffness matrices of each single layer, the stiffness matrices $([A]$ and $[D])$ of the plate, were determined based on the elastic properties of the laminates as given in Table 1. The problem in Figure 2 was solved varying the number of Fourier series terms $(N)$ by creating a for-do cycle. Based on the displacement parameters, the stress resultants and the stresses were calculated, while the ERRs were computed using the $J$-integral. The convergence of the results was analyzed and it was found that after the 13th Fourier term there was no change in the displacement field, stresses, stress resultants and ERRs.

\section{FE model}

In order to verify the analytical results, FE analysis was carried out. The 3D FE model of the plate was created in the code ANSYS 12 using 8-node solid elements. Similar 3D models are documented by de Morais and Pereira $^{22}$ and Pereira and de Morais,${ }^{30}$ therefore the model is not shown here; 50, 78 and 10 elements were 
applied along the plate width $(y)$, length $(x)$ and thickness $(z)$, respectively. The global element size was $2 \mathrm{~mm} \times 2 \mathrm{~mm} \times 0.4 \mathrm{~mm}$. In the vicinity of the crack tip, a refined mesh was constructed including trapezoid shape elements. ${ }^{12}$ The $z$ displacements of the contact nodes over the delaminated surface were imposed to be the same. The mode-II and mode-III ERRs were calculated by the VCCT; the size of the crack tip elements were $\Delta x=0.2 \mathrm{~mm}, \Delta y=0.2 \mathrm{~mm}$ and $\Delta z=2 \mathrm{~mm}$. For the determination of $G_{\text {II }}$ and $G_{\text {III }}$ along the delamination front a so-called MACRO was written in the ANSYS Design and Parametric Language (ADPL). The MACRO gets the nodal forces and displacements at the crack tip at each pair of nodes, respectively, then by defining the size of crack tip elements it determines and plots the ERRs at each node along the crack front.

\section{Analytical and numerical results}

Figure 5 shows the in-plane displacements in the vicinity of two points of the plate: $u(0, b / 2, z)$ and $v(0, b, z)$, i.e. each point lies in the crack front. It is seen that the CLPT underpredicts the FE solution; on the other hand, the FSDT agrees excellently with the FE results. This can be explained by the fact that CLPT does not consider the transverse (or interlaminar) shear effect. Only a small amount of nonlinearity can be observed in the numerical results.

The distribution of the normal stresses, $\sigma_{\mathrm{x}}$ and $\sigma_{\mathrm{y}}$ along the same lines as in Figure 5, are demonstrated in Figure 6. The distributions were determined layerwise using the stress-strain relations given by equation (53). In the case of $\sigma_{\mathrm{x}}$, there are significant differences between the analytical and FE results. The reasons for these discrepancies are the followings. First, the FE solution is based on the nodal stresses, which are calculated by taking the average of the stresses from the eight neighboring elements in the mutual node. That is why it is not possible to obtain piecewise continuous distributions by the FEM. Second, it is seen that although the FEM provides average stresses, the linear approximation is unable to capture accurately the strain and stress states in the vicinity of the delamination front. In a recent paper, ${ }^{53}$ it has been found that second-order plate theory gives much better predictions for the stress state. In the case of $\sigma_{y}$, the agreement between analytical and numerical results is better. Finally, the difference between CLPT and FSDT is

Table I. Elastic properties of single carbon/epoxy laminates.

\begin{tabular}{lccccccccc}
\hline & $E_{x}(\mathrm{GPa}]$ & $E_{y}(\mathrm{GPa})$ & $E_{z}(\mathrm{GPa})$ & $G_{y z}(\mathrm{GPa})$ & $G_{x z}(\mathrm{GPa})$ & $G_{x y}(\mathrm{GPa})$ & $v_{y z}$ & $v_{x z}$ & $v_{x y}$ \\
\hline $\pm 45^{\circ f}$ & 16.39 & 16.39 & 16.4 & 5.46 & 5.46 & 16.4 & 0.5 & 0.5 & 0.3 \\
$0^{\circ}$ & 148 & 9.65 & 9.65 & 4.91 & 4.66 & 3.71 & 0.27 & 0.25 & 0.3 \\
\hline
\end{tabular}
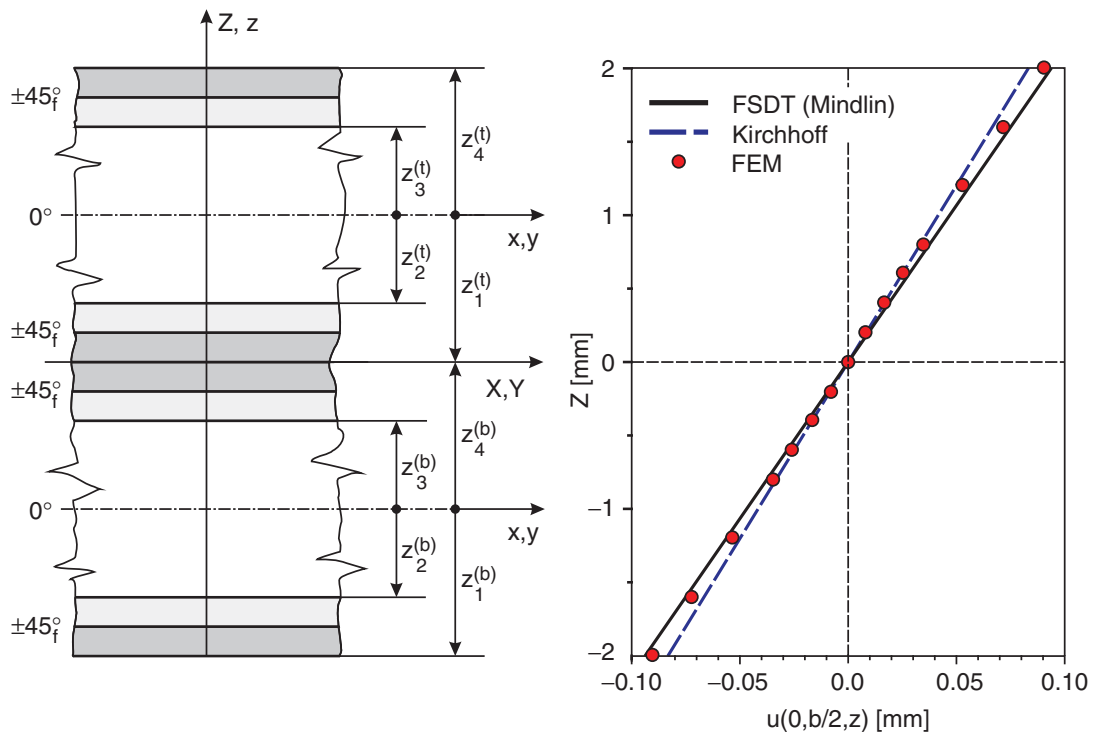

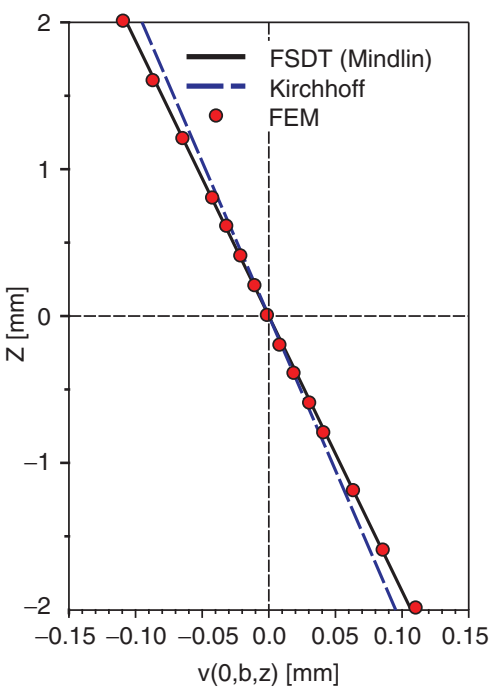

Figure 5. Distribution of the in-plane displacements over the plate thickness. 
not significant. It has to be mentioned that in the FE model, the displacement and stress continuity is ensured, but in the analytical models only the continuity of displacement parameters and shear forces $Q_{\mathrm{x}}, Q_{\mathrm{y}}$ (FSDT) can be realized.

Consequently, the stresses are not continuous in accordance with either the CLPT or FSDT, however, the discrepancies in stresses are not so significant in the transition between the delaminated and undelaminated plate portions.

The distributions of transverse shear stresses are plotted in Figure 7. The FE solution, the solution by
FSDT (piecewise constant, purple line) as well as the solution calculated by the $3 \mathrm{D}$ equilibrium equations are equally presented. The latter ones were calculated by the $\underline{\sigma} \nabla=\underline{0}$ equation $^{2,49}$ including both theories. The mismatch between the FE and analytical solutions is significant, especially in the interface plane of the plate, where the FE model predicts a sharp peak. From another point of view, the FSDT and 3D equilibrium solutions agree well, while the CLPT predicts negligible shear stresses. The disagreement between the numerical and analytical models is attributed to the fact that the assumed linear displacement field in terms of $z$
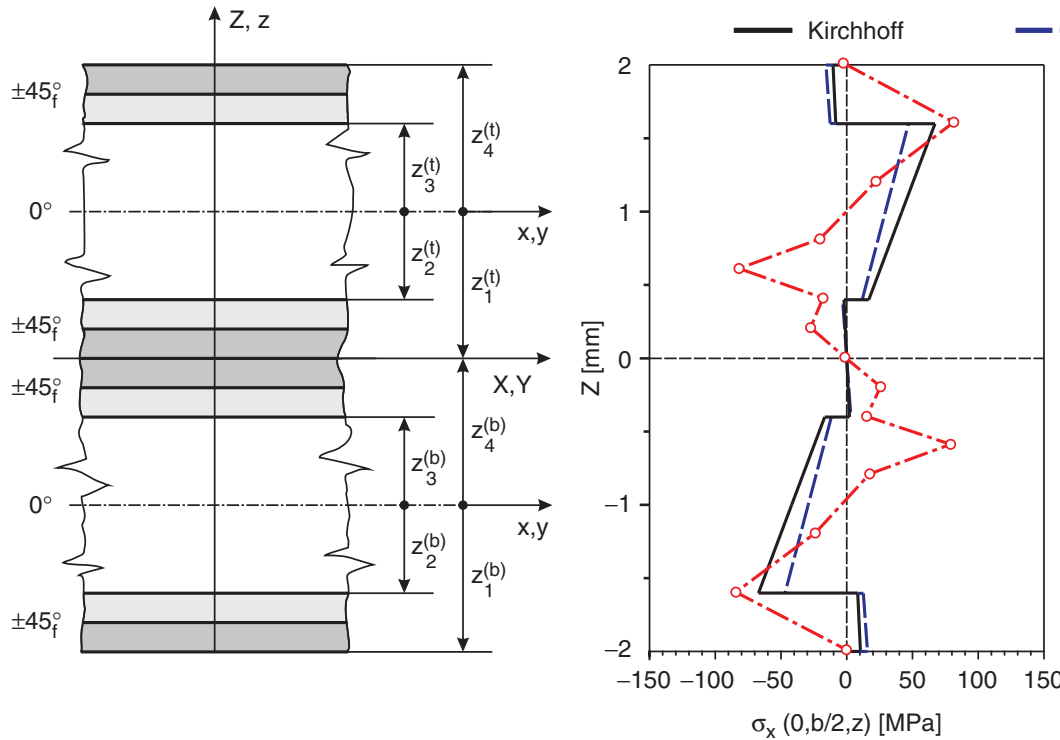

Figure 6. Distribution of the normal stresses over the plate thickness.
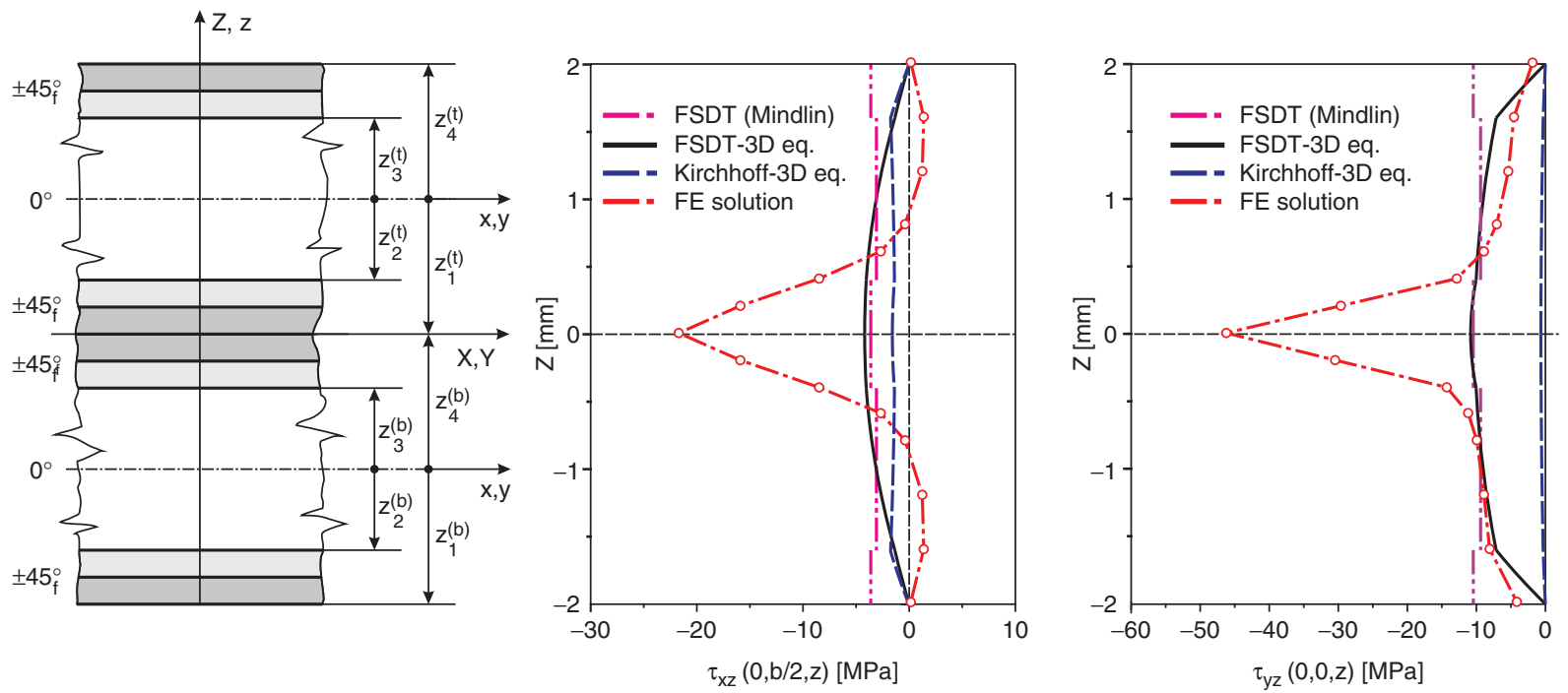

Figure 7. Distributions of shear stresses over the plate thickness.

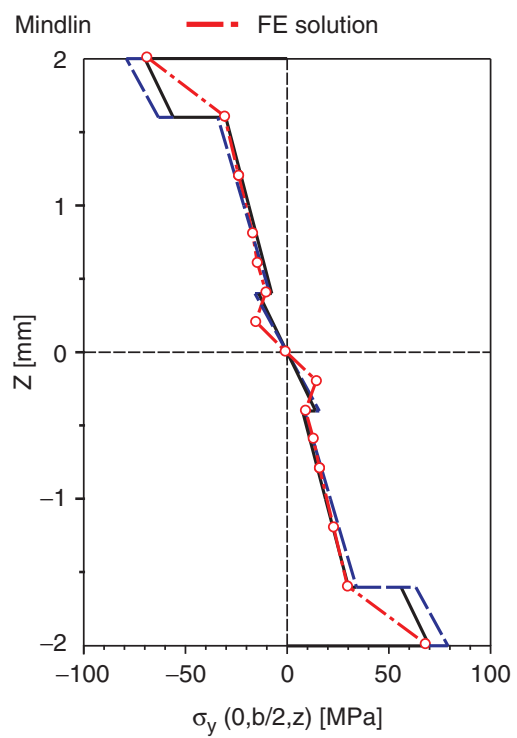


is unable to provide better results. The distributions of the in-plane normal force $N_{\mathrm{x}}(\mathrm{x}, \mathrm{y})$ and the shear force $N_{\mathrm{xy}}(x, y)$ are plotted in Figure 8.

Although these stress resultants could be calculated by the FE model too (by integrating the normal and inplane shear stresses in the through-thickness direction), this would be a very long process, therefore, in this case only analytical results are presented. It is seen that near the delamination front $(x=0)$ these stress resultants change suddenly and significantly. Moreover, $N_{\mathrm{x}}$ involves the $\sin$, while $N_{\mathrm{xy}}$ involves the $\cos$ function (refer to equation (43)) leading to the completely different nature of these stress resultants. One of the advantages of plate theory over the FE model is that these plots can be obtained very simply in the analytical way. Considering the values, the difference between the CLPT (Figure 8(a) and (b)) and FSDT (Figure 8(c) and (d)) theories is significant. The FSDT theory indicates that the stress resultants change more suddenly at the crack front $(x=0)$ compared to the CLPT. The reason for that is again the fact that transverse shear effect is not considered by CLPT, and the absence of the independent rotational parameters results in the discrepancies between the stress resultants presented in Figure 8(a)-(d). Also, the different displacement fields of CLPT and FSDT lead to different equilibrium equations (compare equation (18)-(20) and (29)) and so different stress resultants.

The interlaminar shear stress (=transverse shear in accordance with the duality of shear stresses) distributions along the global midplane of the undelaminated plate portion (top plate, refer to Figure 1) can be calculated based on the FSDT as:

$$
\begin{aligned}
& \left.\tau_{\mathrm{xz}}\right|_{z=-\frac{t}{2}}=G_{13}^{ \pm 45} \gamma_{\mathrm{xz}}=G_{13}^{ \pm 45}\left(\theta_{x 2}+\frac{\partial w_{2}}{\partial x}\right), \\
& \left.\tau_{\mathrm{yz}}\right|_{z=-\frac{t}{2}}=G_{23}^{ \pm 45} \gamma_{\mathrm{yz}}=G_{23}^{ \pm 45}\left(\theta_{y 2}+\frac{\partial w_{2}}{\partial y}\right)
\end{aligned}
$$

where the shear moduli are defined in Table 1. The function plots are given by Figure 9. Both stresses change significantly near the delamination front and (a)

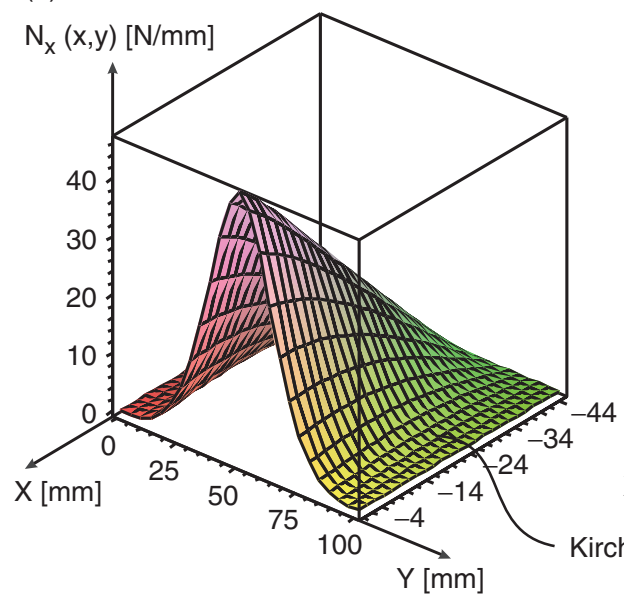

(c)

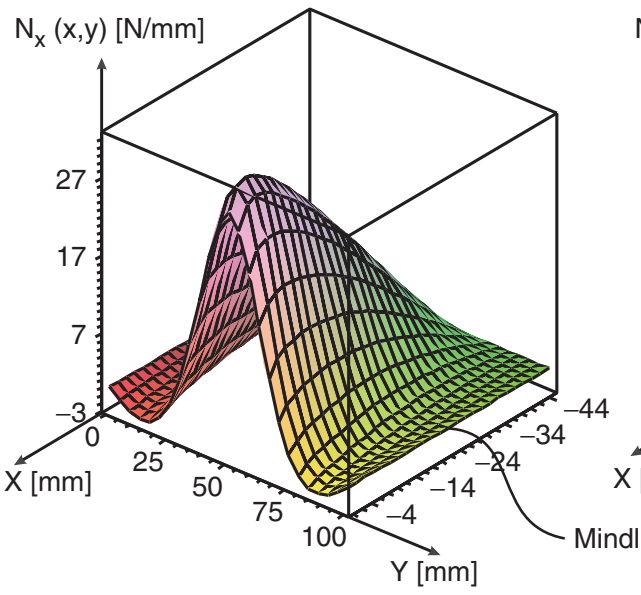

(b)

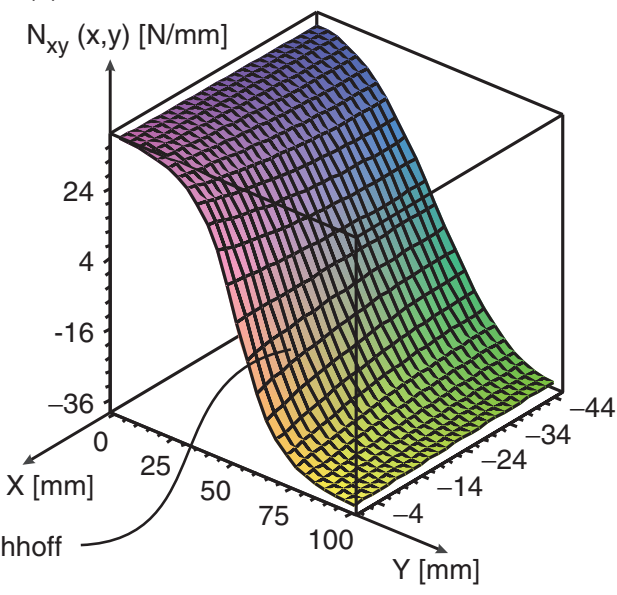

(d)

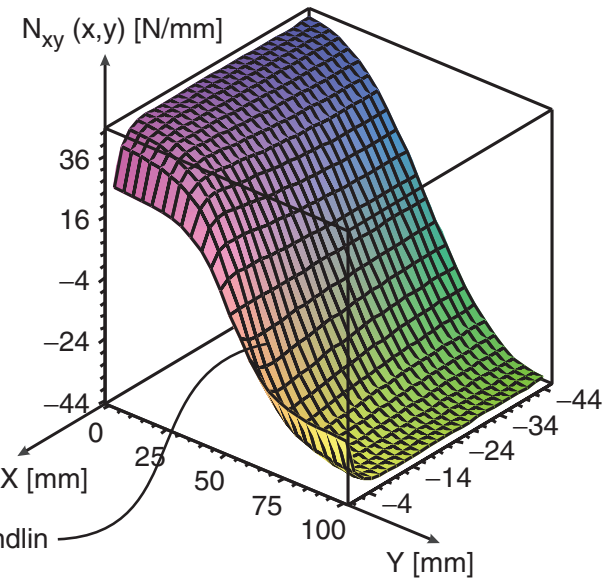

Figure 8. Distribution of the in-plane normal and shear forces over the uncracked (top) plate portions. 
decay suddenly by getting far from it. It is important to note that $\tau_{\mathrm{xz}}$ does not vanish at the $x=-c$ boundary, on the other hand, $\tau_{\mathrm{yz}}$ vanishes entirely at the same location.

The mode-II, mode-III ERRs and the mode ratio along the delamination front are plotted in Figure 10. The symbols show the results of the VCCT, while the curves represent the results by CLPT and FSDT. According to Figure 10(a), it can be seen that the CLPT produces some overprediction for $G_{\mathrm{II}}$ compared to the VCCT but underpredicts significantly $G_{\text {III }}$. We note that in accordance with equations (58) and (56), the ERR by $M_{\mathrm{xy}}$ vanishes in the case of CLPT. The reason for that is the continuity of the derivative of the deflections in equation (45) in the transition zone and that both the twisting moment and twisting curvature are proportional to this derivative. Consequently, in the case of CLPT $G_{\text {III }}$ comes from the in-plane shear force $N_{\mathrm{xy}}$ only. Seeing the results by FSDT, a better agreement with the numerical results is obtained. Although the mode-II ERR compared to the VCCT result is significantly underpredicted, the overall agreement is acceptable. These results show that a displacement field with at least five parameters (three parameters with interface constraints) is necessary to reach an acceptable agreement with the VCCT results. The mode ratios are plotted in Figure 10(b). The main conclusion is that the FSDT captures this ratio even better than CLPT. It is important to mention that the VCCT method is mesh-sensitive to a certain degree and the investigation of the effect of mesh refinement was outside the scope of this paper. (a)

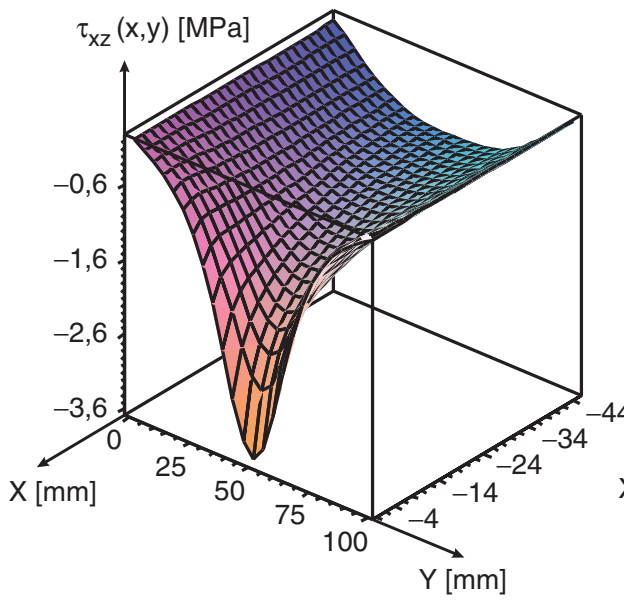

(b)

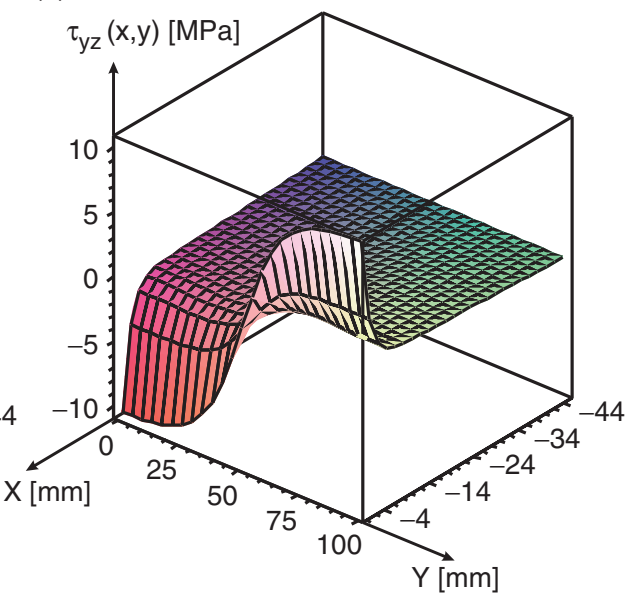

Figure 9. Distribution of the interlaminar shear stresses over the uncracked (top) plate portion.

(a)

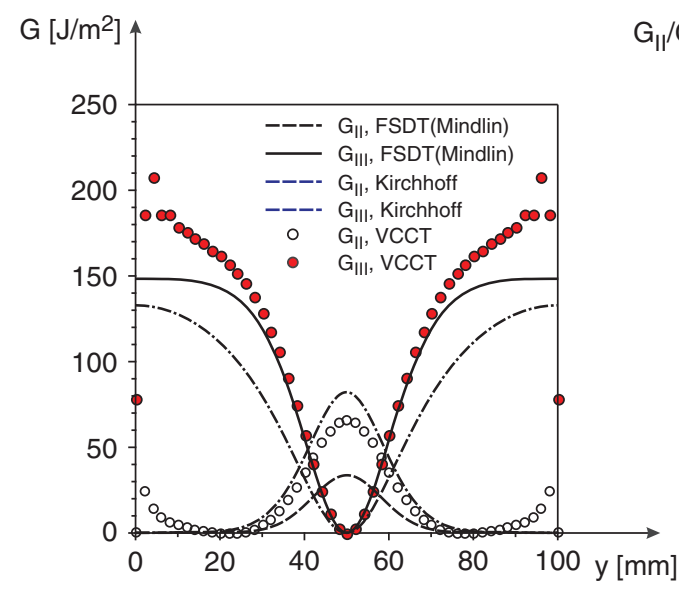

(b)

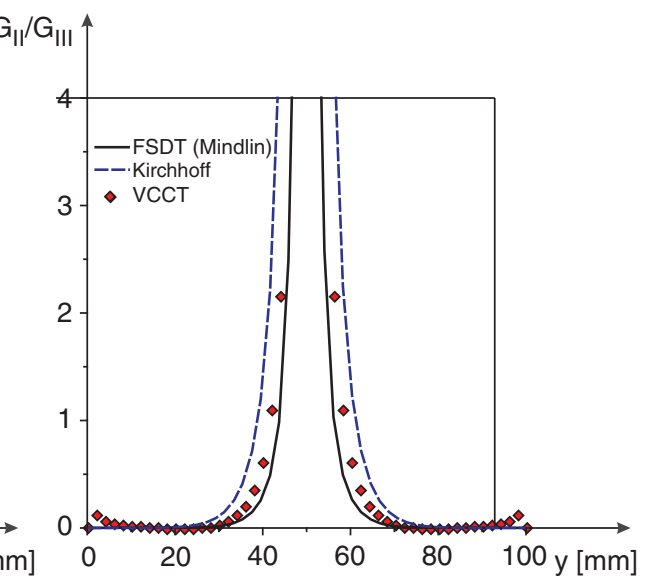

Figure 10. Distribution of the ERRs and the mode ratio by CLPT, FSDT and VCCT. ERR: energy release rate; CLPT: classical laminated plate theory; FSDT: first-order shear deformable plate theory; VCCT: virtual-crack closure technique. 
(a)

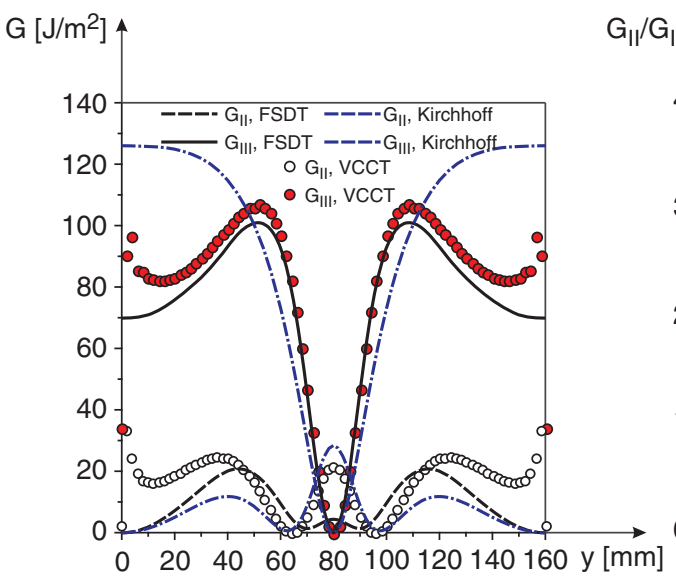

(b)

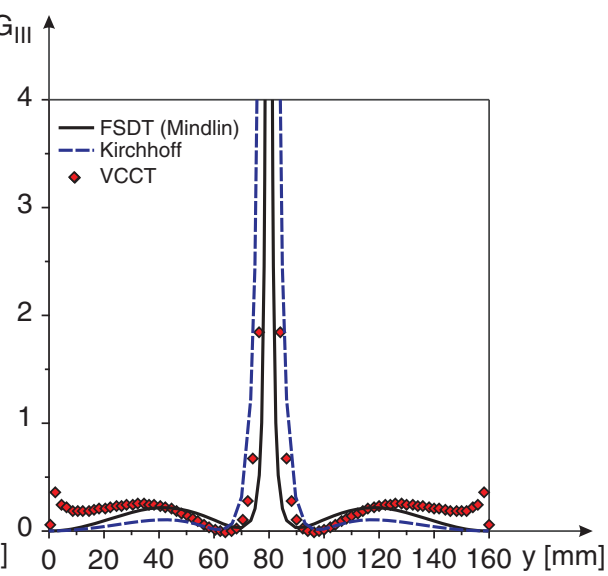

Figure II. Distribution of the ERRs and the mode ratio by CLPT, FSDT and VCCT $(b=160 \mathrm{~mm})$. ERRs: energy release rate; CLPT: classical laminated plate theory; FSDT: first-order shear deformable plate theory; VCCT: virtual-crack closure technique.

For the sake of completeness, the ERRs and mode ratios were also calculated for the case when the plate width was $b=160 \mathrm{~mm}$. The results are presented in Figure 11. Although the CLPT captures better the mode-II ERR in the middle part of the plate, the mode-III ERR differs significantly in comparison with the FE results. The FSDT provides better results, especially in the case of $G_{\mathrm{III}}$. Independent of the fact whether the CLPT or FSDT theory is utilized, the analytical models do not capture the edge effect. More clearly, the FE solution indicates some oscillatory change at the plate edges; on the contrary, the analytical solutions remain smooth. The final conclusion is that the transverse (or interlaminar) shear effect plays an important role in the development of an accurate plate model to analyze delaminated composite plates even in that case when the plate is relatively thin.

\section{Conclusions}

The classical laminated and first-order shear deformable plate theories are utilized in this work to develop a double-plate system for delaminated orthotropic composite plates. The models are based on the continuity of the displacement field across the delamination front by imposing the kinematic constraints along the interface. A simply-supported delaminated plate subjected to a point force was analyzed using Lévy plate formulation, the stresses and the ERRs were calculated. The results were compared to those of a 3D FE model and a comparison was made among the results obtained. The final conclusion is that transverse shear effect and the coupling between the stress resultants play important role in the development of an accurate plate model for delaminated composite plates.
The present model eliminates the physically inconsistent shear compliance of the flexible joint models and includes the effect of interface deformation based on the equations of linear elasticity and the material law of orthotropic solids. It was shown that although the displacement components are continuous across the delamination, there are stress resultants, which remain discontinuous. Moreover, the shear forces vanish in the $J$-integral, and the mode-II and mode-III ERRs are defined in a relatively simple way. However, it must be mentioned that only mixed-mode II/III fracture problems were considered in this study and the transverse deflection of the top and bottom plates was considered to be the same. It has been shown that the difference between the FE and plate theory solution becomes the largest at the edges of the plate.

Considering the available methods for the calculation of the ERR in plates, the first alternative is in general the VCCT. However, for the 3D FE model, the computation could be lengthy, especially if the model size is relatively large. Furthermore, in the crack tip a refined mesh should be constructed to obtain accurate ERR values. Finally, in most of the commercial FE packages, the VCCT has not yet been implemented. The present work provides another possibility for the calculation of the ERR in plates subjected to bending. The possible application field of the presented method is the fracture mechanics of composite materials. In the last few years, fracture test methods including plate-like specimens have been developed to characterize the mode-III, mixed-mode II/III and mixed-mode I/III fracture behavior of laminated materials. ${ }^{18,22,30}$ By preparing a detailed user-friendly worksheet in MAPLE, it is possible to provide a data reduction scheme for the experimentalists. Also, the 
application to asymmetrically delaminated orthotropic and angle-ply laminated plates as well as sandwich panels needs to be investigated. The present model can be implemented in the vibration analysis of simply-supported composite plates too. Finally, the analysis developed in this paper may be utilized as a means for benchmarking fracture mechanical tools ${ }^{54}$ that are available in commercial FE packages. These tasks will be carried out in the near future.

\section{Acknowledgments}

This work was supported by the János Bolyai Research Scholarship of the Hungarian Academy of Sciences. This work is connected to the scientific program of the "Development of quality-oriented and harmonized $\mathrm{R}+\mathrm{D}+\mathrm{I}$ strategy and functional model at BME" project. This project is supported by the New Hungary Development Plan (Project ID: TÁMOP-4.2.1/B-09/1/KMR-2010-0002).

\section{Conflict of Interest}

None declared.

\section{Funding}

This research received no specific grant from any funding agency in the public, commercial, or not-for-profit sectors.

\section{References}

1. Kollár LP and Springer GS. Mechanics of composite structures. Cambridge, New York, Melbourne, Madrid, Cape Town, Singapore, São Paolo, PA: Cambridge University Press, 2003.

2. Reddy JN. Mechanics of laminated composite plates and shells - Theory and analysis. Boca Raton, London, New York, Washington DC, PA: CRC Press, 2004.

3. Rudolph Sz. Theories and applications of plate analysis. Hoboken, New Jersey, PA: John Wiley \& Sons, 2004.

4. Carlsson LA and Kardomateas GA. Structural and failure mechanics of sandwich composites. Dordrecht, Heidelberg, London, New York. PA: Springer, 2004.

5. Anderson TL. Fracture mechanics-fundamentals and applications, 3rd edn. Boca Raton, London, New York, Singapore, PA: CRC Press, Taylor \& Francis Group, 2005.

6. Jumel J, Budzik MK and Shanahan MER. Beam on elastic foundation with anticlastic curvature: Application to analysis of mode I fracture tests. Eng Fract Mech 2011; 78: 3253-3269.

7. Peng L, Zhang J, Zhao L, et al. Mode I delamination growth of multidirectional composite laminates under fatigue loading. J Compos Mater 2011; 45: 1077-1090.

8. Wang $\mathbf{J}$ and Qiao P. Novel beam analysis of the end notched flexure specimen for mode-II fracture. Eng Fract Mech 2004; 71: 219-231.

9. Argüelles A, Viña J, Canteli AF, et al. Influence of resin type on the delamination behavior of carbon fiber reinforced composites under mode-II loading. Int $J$ of Damage Mech 2011; 20(7): 963-978.
10. Plain KP and Tong L. An experimental study on mode I and II fracture toughness of laminates stitched with a one-sided stitching technique. Compos Part A Appl Sci Manufact 2011; 42: 203-210.

11. Reeder JR and Crews JR. Mixed-mode bending method for delamination testing. AIAA J 1990; 28: 1270-1276.

12. Davidson BD and Sundararaman V. A single leg bending test for interfacial fracture toughness determination. Int $J$ Fract 1996; 78: 193-210.

13. Lee SM. An edge crack torsion method for mode III delamination fracture testing. J Compos Technol Res 1993; 15: 193-201.

14. Li J and O'Brien TK. Simplified data reduction methods for the ECT test for mode III interlaminar fracture toughness. J Compos Technol Res 1996; 18: 96-101.

15. Szekrényes A. Improved analysis of the modified splitcantilever beam for mode III fracture. Int $J$ Mech $\mathrm{Sci}$ 2009; 51: 682-693.

16. Browning G, Carlsson LA and Ratcliffe JG. Modification of the edge crack torsion specimen for mode III delamination testing. Part II-experimental study. J Compos Mater 2011; 45: 2633-2640.

17. Browning G, Carlsson LA and Ratcliffe JG. Redesign of the ECT test for mode III delamination testing. Part I: Finite element analysis. J Compos Mater 2010; 44: 1867-1881.

18. de Morais AB and Pereira AB. Mode III interlaminar fracture of carbon/epoxy laminates using a four-point bending plate test. Compos Part A Appl Sci Manufact 2009; 40: 1741-1746.

19. de Moura MFSF, Fernandez MVC, de Morais AB, et al. Numerical analysis of the edge crack torsion test for mode III interlaminar fracture of composite laminates. Eng Fract Mech 2009; 76: 469-478.

20. Mehrabadi FA and Khosravan M. Mode III interlaminar fracture and damage characterization in woven fabricreinforced glass/epoxy composite laminates. J Compos Mater 2013; 47(13): 1583-1592.

21. Szekrényes A. Delamination fracture analysis in the $G_{\text {II }}-G_{\text {III }}$ plane using prestressed composite beams. Int $J$ Solid Struct 2007; 44: 3359-3378.

22. de Morais AB and Pereira AB. Mixed mode II + III interlaminar fracture of carbon/epoxy laminates. Compos Sci Technol 2008; 68: 2022-2027.

23. Kondo A, Sato Y, Suemasu H, et al. Characterization of fracture resistance of carbon/epoxy composite laminates during mixed-mode II and III stable damage propagation. J Jpn Soc Compos Mater 2010; 36(5): 179-188.

24. Suemasu H, Kondo A, Gozu K, et al. Novel test method for mixed mode II and III interlaminar fracture toughness. Adv Compos Mater 2010; 19(4): 349-361.

25. Suemasu H, Kondo A, Gozu K, et al. Double notched split cantilever test method to measure the mixed mode II and III interlaminar toughness. In: ICCM-17 17th International Conference on Composite Materials. Paper ID. F9.6. 27 Jul 2009-31 Jul 2009, pp. 1-10, Edinburgh International Convention Centre (EICC), Edinburgh, UK. 
26. Kondo A, Sato Y, Suemasu H, et al. Fracture resistance of carbon/epoxy composite laminates under mixed-mode II and III failure and its dependence on fracture morphology. Adv Compos Mater 2011; 20(5): 405-418.

27. Szekrényes A. Interlaminar fracture analysis in the GIIGIII plane using prestressed composite beams. Compos Part A Appl Sci Manufact 2012; 43: 95-103.

28. Miura M, Shindo Y, Takeda T, et al. Interlaminar fracture characterization of woven glass/epoxy composites under mixed-mode II/III loading conditions at cryogenic temperatures. Eng Fract Mech 2012; 96: 615-625.

29. Mehrabadi FA. Analysis of pure mode III and mixed mode (III+II) interlaminar crack growth in polymeric woven fabrics. Mater Design 2013; 44: 429-437.

30. Pereira AB and de Morais AB. Mixed-mode I + III interlaminar fracture of carbon/epoxy laminates. Compos Part A Appl Sci Manufact 2009; 40: 518-523.

31. Szekrényes A. Interlaminar fracture analysis in the $G_{I^{-}} G_{\text {III }}$ plane using prestressed composite beams. Compos Part A Appl Sci Manufact 2009; 40: 1621-1631.

32. Davidson BD, Sediles FO and Humphreys KD. A sheartorsion-bending test for mixed-mode I-II-III delamination toughness determination. In: 25th Technical Conference of the American Society for Composites and 14th US-Japan Conference on Composite Materials (ed JB Lantz), 2010, 2, pp.1001-1020. Curran Associates, Inc.

33. Szekrényes A. Interlaminar fracture analysis in the $G_{I^{-}}$ $G_{\text {II }}-G_{\text {III }}$ space using prestressed composite beams. $J$ Reinf Plast Compos 2011; 30: 1655-1669.

34. Davidson BD and Sediles FO. Mixed-mode I-II-III delamination toughness determination via a shear-torsion-bending test. Compos Part A Appl Sci Manufact 2011; 42: 589-603.

35. Davidson BD, $\mathrm{Yu} \mathrm{L}$ and $\mathrm{Hu} \mathrm{H}$. Determination of energy release rate and mode mix in three-dimensional layered structures using plate theory. Int J Fract 2000; 105: 81-104.

36. Sankar BV and Sonik V. Pointwise energy release rate in delaminated plates. AIAA J 1995; 33: 1312-1318.

37. Park O and Sankar BV. Crack-tip force method for computing energy release rate in delaminated plates. Compos Struct 2002; 55: 429-434.

38. Pao YC. Simple bending analysis of laminated plates by large-deflection theory. $J$ Compos Mater 1970; 4: 380-389.

39. Whitney JM. The effect of transverse shear deformation ont he bending of laminated plates. J Compos Mater 1969; 3: 534-547.

40. Shi G and Bezine G. A general boundary integral formulation for the anisotropic plate bending problems. $J$ Compos Mater 1988; 22: 694-716.

41. Qiao P and Wang J. Mechanics and fracture of crack-tip deformable bimaterial interface. Int J Solid Struct 2004; 41: 7423-7444.

42. Wang $\mathbf{J}$ and Qiao $P$. Interface crack between two shear deformable elastic layers. J Mech Phys Solid 2004; 52: 891-905.
43. Qiao P and Chen F. On the compliance and energy release rate of generically-unified beam-type fracture specimens. J Compos Mater 2011; 45(1): 65-101.

44. Chen F. Interface mechanics of layered composite beamtype structures. $\mathrm{PhD}$ Thesis. Department of Civil and Environmental Engineering, Washington State University, 2011.

45. Szekrényes A. Interlaminar stresses and energy release rates in delaminated orthotropic composite plates. Int $J$ Solid Struct 2012; 49: 2460-2470.

46. Szekrényes A. Interface crack between isotropic Kirchhoff plates. Meccanica 2013; 48(3): 507-526.

47. Rice JR. A path independent integral and the approximate analysis of strain concentration by notches and cracks. J Appl Mech 1968; 35: 379-386.

48. Cherepanov GP. Methods of fracture mechanics: Solid matter physics. Dordrecht, Boston, London, PA: Kluwer Academic Publishers, 1997.

49. Chou PC and Pagano NJ. Elasticity-tensor, dyadic, and engineering approaches. Princeton, New Jersey, Toronto, London, PA: D. Van Nostrand Company Inc, 1967.

50. Rigby $\mathrm{RH}$ and Aliabadi MH. Decomposition of the mixed-mode J-integral-revisited. Int $J$ Solid Struct 1998; 35: 2073-2099.

51. Shivakumar KN and Raju IS. An equivalent domain integral method for three- dimensional mixed-mode fracture problems. Eng Fract Mech 1992; 42: 935-959.

52. Garvan F. The Maple Book. Boca Raton, London, New York, Washington DC, PA: Chapman \& Hall/CRC, 2002.

53. Szekrényes A. Interface fracture in orthotropic composite plates using second-order shear deformation theory. Int $J$ Damage Mech 2013; 22(8): 1161-1185.

54. Orifici A and Krueger R. Benchmark assessment of automated delamination propagation capabilities in finite element codes for static loading. Finite Element Anal Design 2012; 54: 28-36.

\section{Appendix I}

Coefficients for equations (21)-(23) and (38)

$$
\begin{aligned}
\hat{a}_{1} & =A_{11} t^{2} / 4+D_{11}, \hat{a}_{2}=A_{66} t^{2} / 4+D_{66}, \hat{a}_{3}=\hat{a}_{5} \\
& =-k A_{55}, \hat{a}_{4}=\left(A_{12}+A_{66}\right) t^{2} / 4+D_{12}+D_{66} \\
\hat{b}_{1} & =\hat{a}_{4}, \hat{b}_{2}=\hat{a}_{2}, \hat{b}_{3}=A_{22} t^{2} / 4+D_{22}, \hat{b}_{4}=\hat{b}_{5}=-k A_{44} \\
\hat{c}_{1} & =\hat{c}_{3}=k A_{55}, \hat{c}_{2}=\hat{c}_{4}=k A_{44}, \hat{c}_{5}=1 \\
\hat{d}_{1} & =\left(\beta^{2} \hat{a}_{2}-\hat{a}_{3}\right) / \hat{a}_{1}, \hat{d}_{2}=\beta \hat{a}_{4} / \hat{a}_{1}, \hat{d}_{3}=-\hat{a}_{5} / \hat{a}_{1} \\
\hat{e}_{1} & =-\beta \hat{b}_{1} / \hat{b}_{2}, \hat{e}_{2}=\left(\beta^{2} \hat{b}_{3}-\hat{b}_{4}\right) / \hat{b}_{2}, \hat{e}_{3}=-\beta \hat{b}_{5} / \hat{b}_{2} \\
\hat{f}_{1} & =-\hat{c}_{1} / \hat{c}_{3}, \hat{f}_{2}=\beta \hat{c}_{2} / \hat{c}_{3}, \hat{f}_{3}=\beta^{2} \hat{c}_{4} / \hat{c}_{3}, \hat{f}_{4}=-\hat{c}_{5} / \hat{c}_{3}
\end{aligned}
$$




\section{Appendix 2}

Coefficients for equation (34)

$$
a_{1}=A_{11}, a_{2}=A_{66}, a_{3}=A_{12}+A_{66},
$$

$b_{1}=a_{3}, b_{2}=a_{2}, b_{3}=A_{22}$

$c_{1}=D_{11}, c_{2}=D_{66}, c_{3}=c_{5}=-k A_{55}, c_{4}=D_{12}+D_{66}$

$d_{1}=c_{4}, d_{2}=c_{2}, d_{3}=D_{22}, d_{4}=d_{5}=-k A_{44}$

$e_{1}=e_{2}=k A_{55}, e_{2}=e_{4}=k A_{44}, e_{5}=1$

$f_{1}=\beta^{2} a_{2} / a_{1}, f_{2}=\beta a_{3} / a_{1}$

$g_{1}=-\beta b_{1} / b_{2}, g_{2}=\beta^{2} b_{3} / b_{2}$

$h_{1}=\left(\beta^{2} c_{2}-c_{3}\right) / c_{1}, h_{2}=\beta c_{4} / c_{1}, h_{3}=-c_{5} / c_{1}$

$j_{1}=-\beta d_{1} / d_{2}, j_{2}=\left(\beta^{2} d_{3}-d_{4}\right) / d_{2}, j_{3}=-\beta d_{5} / d_{2}$

$k_{1}=-e_{1} / e_{3}, k_{2}=\beta e_{2} / e_{3}, k_{3}=\beta^{2} e_{4} / e_{3}, k_{4}=-e_{5} / e_{3}$ 